\title{
String Flash-Boiling in Gasoline Direct Injection Simulations with Transient Needle Motion
}

\author{
E.T. Baldwin ${ }^{\mathrm{a}, *}$, R.O. Grover, Jr. ${ }^{\mathrm{b}}$, S.E. Parrish ${ }^{\mathrm{b}}$, D.J. Duke ${ }^{\mathrm{c}}$, K.E. \\ Matusik $^{\mathrm{c}}$, C.F. Powell ${ }^{\mathrm{c}}$, A.L. Kastengren ${ }^{\mathrm{d}}$, D.P. Schmidt ${ }^{\mathrm{a}}$ \\ ${ }^{a}$ University of Massachusetts, Amherst MA USA 01003 \\ ${ }^{b}$ General Motors Research and Development, Warren MI USA 48090 \\ ${ }^{c}$ Energy Systems Division, Argonne National Laboratory, Lemont IL USA 60439 \\ ${ }^{d}$ X-ray Science Division, Argonne National Laboratory, Lemont IL USA 60439
}

\begin{abstract}
A computational study was performed to investigate the influence of transient needle motion on gasoline direct injection (GDI) internal nozzle flow and near-field sprays. Simulations were conducted with a compressible Eulerian flow solver modeling liquid, vapor, and non-condensable gas phases with a diffuse interface. Variable rate generation and condensation of fuel vapor were captured using the homogeneous relaxation model (HRM). The non-flashing (spray G) and flashing (spray G2) conditions specified by the Engine Combustion Network were modeled using the nominal spray G nozzle geometry. Transient needle lift and wobble were based upon ensemble averaged X-ray imaging preformed at Argonne National Lab. The minimum needle lift simulated was $5 \mu \mathrm{m}$ and dynamic mesh motion was achieved with Laplacian smoothing. The results were qualitatively validated against experimental imaging and the experimental rate of injection profile was captured accurately using pressure boundary conditions and needle motion to actuate the injection. Low needle lift is shown to result in vapor generation near the injector seat. Finally, the internal injector flow is shown to be highly complex, containing many transient and interacting vortices which result in perturbations in the spray angle and fluctuations in the mass flux. This complex internal flow also results in intermittent string flash-boiling when a strong vortex is injected and the resulting swirling spray contains a thermal
\end{abstract}

\footnotetext{
* Corresponding author

Email address: ebaldwin@umass.edu (E.T. Baldwin)
}

Preprint submitted to International Journal of Multiphase Flow

July 18, 2016

(C) 2016. This manuscript version is made available under the Elsevier user license http://www.elsevier.com/open-access/userlicense/1.0/ 
non-equilibrium vapor core.

Keywords: Gasoline Direct Injection, Flash-Boiling, Diffuse Interface, CFD, OpenFOAM ${ }^{\circledR}$

\section{Introduction}

\subsection{Background}

In recent years there has been a trend in the automotive industry towards the use of gasoline direct injection (GDI) engines. This injection configuration allows for more control over the combustion process, which leads to increased fuel economy. While GDI engines have developed significantly since their inception, there is still work to be done. The desire to further reduce emissions and maximize fuel efficiency demands continued improvement.

The injection process is very important because it is the first step in the combustion process. Here high pressure fuel flows though the injector and sprays directly into the combustion chamber. The complexity of this process is due to multiple factors. First, the geometries of GDI injectors are typically quite elaborate; multi-hole stepped valve covered orifice (SVCO) injectors are common. This, in conjunction with the high injection pressures, leads to turbulent flows which often exhibit slight asymmetry and hole-to-hole variation as they leave the nozzle $[43,8]$. Furthermore, as the liquid fuel is injected it can undergo phase change through cavitation, flash-boiling, and/or evaporation. Significant research has been done to understand the highly turbulent, cavitating, and evaporating sprays present in direct injection (DI) diesel engines, and while there is some overlap between diesel DI and GDI, it is the added factor of phase change through flash-boiling that makes GDI research especially challenging.

\subsection{Vapor generation}

Vaporization takes place at small length scales and is influenced by the complex interfacial and turbulent dynamics of the flow. Moreover, phase change occurs at different rates depending on the properties of the flow. The vapor pressure and vapor density of a cold fluid is typically very low. Because of this, very little heat transfer is required per volume of vapor, and cavitation, which occurs at low temperatures, is a fast, inertially driven process which tends to be at or near thermodynamic equilibrium. On the other hand, the vapor density of a hot liquid is much higher. Consequently, 
more heat transfer is required per volume of vapor and flash-boiling is a thermally driven non-equilibrium process. This can be understood further with the help of the non-dimensional Jakob number which is the ratio of the sensible heat available to the latent heat required for vaporization [28].

$$
J a=\frac{\rho_{l} C_{p} \Delta T}{\rho_{v} h_{f g}}
$$

Here $\rho_{l}$ is the liquid density, $\rho_{v}$ is the vapor density, $C_{p}$ is the specific heat at constant pressure, $\Delta T$ is the degree of superheat, and $h_{f g}$ is the enthalpy of vaporization. When the Jakob number is high there will be an abundance of energy available in the liquid to generate vapor. This means that heat transfer time scales will be much smaller than flow time scales and it can be assumed that the flow is at thermal equilibrium. Alternatively, when the Jakob number is low, heat transfer time scales will be of the same order as that of the flow and thermal equilibrium cannot be assumed.

In a modern GDI engine, a wide range of Jakob numbers can be present. This is due to the wide range of operating conditions that an engine will encounter. Fuel temperatures can vary from below $0^{\circ} \mathrm{C}$ during a cold start on a winter day, to upwards of $90^{\circ} \mathrm{C}$ under high engine load. In-cylinder temperature and pressure can also vary significantly depending on whether injection occurs early during the intake stroke for homogeneous combustion, or late in the compression stroke for stratified, highly lean local combustion. Depending on the combination of fuel temperature and downstream pressure, the degree to which the spray is flash-boiling will vary. This means that GDI engines must be designed to utilize hard flashing, moderately flashing, and sub-cooled sprays.

\subsection{Literature review: experimental}

A multitude of experimental studies have attempted to characterize the behavior of flash-boiling sprays. Among them, it is commonly observed that the spray structure is completely altered by flash-boiling conditions; penetration is reduced, atomization and spray angle are increased, and often a large recirculating toroidal vortex is present around the tip of the jet [32, 41, 48]. Compared to non-flashing conditions, where the Weber number and Reynolds number are highly important [52], under flashing conditions Zeng et al. [51] and $\mathrm{Xu}$ et al [48] have shown that it is the ambient to saturated pressure ratio $\left(\mathrm{P}_{\mathrm{a}} / \mathrm{P}_{\mathrm{s}}\right)$ which correlates well with spray characteristics. 
Experimental studies done on multi-hole injectors commonly observe a collapse of the spray under hard flashing conditions $[53,51,2,45,31,39$, 3]. This collapse typically occurs at or below $\left(\mathrm{P}_{\mathrm{a}} / \mathrm{P}_{\mathrm{s}}\right)$ of 0.3 as the quickly expanding spray plumes interact with one another [51]. The collapse of these sprays alters the designed directionality of the injectors and inhibits mixing with the ambient gas. Hole-to-hole variation in mass flow rate [43] and spray plume structure [8] are also commonly observed. In such cases, it is possible that factors such as asymmetry in the nozzle geometry and the manufacturing defects work together to generate asymmetry in the flow.

Many experimental studies describe their observations with semi-empirical zero or one-dimensional models [30, 41, 24, 52, 48]. These are beneficial to an extent, however, they will never be able to represent the sprays generated by the complex geometries present in production injectors. Consider, for example, the significant influence something as subtle as manufacturing imperfections can have on sprays: Kastengren et al. observed differences in sprays from nominally identical diesel injectors [20], and Zhang et al. observed differences in GDI sprays from nominally identical injectors which were fabricated with different techniques [54]. Capturing the influence of such subtle differences is beyond the scope of lower order models, however CFD can capture these effects [49]. For this reason, CFD simulations have an important role to play, both as an engineering design tool and in the academic investigation into the complex physics occurring within these sprays.

\subsection{Literature review: computational}

Eulerian CFD spray models have become increasingly popular in recent years. These models have the benefit of easily capturing the internal nozzle flow and external spray in a single simulation. Depending on how the model is designed to handle the multiphase interface it can either be classified as a sharp interface or a diffuse interface model.

Sharp interface models use a variety of numerical techniques to attempt to maintain and reconstruct the interface. This approach is appealing because it relies on first principles and the interfacial effects are directly simulated. These models are a beneficial tool in helping to understand the underlying mechanisms which determine a nozzle's spray characteristics. For example Shost et al. [42] and Befrui et al. [5] used a VOF-LES model to simulate GDI sprays and elucidate the influence of nozzle geometry, flow turbulence, and aerodynamic instabilities on GDI sprays. 
Unfortunately, this approach faces two significant drawbacks when applied to spray modeling. First, it can be prohibitively expensive as it requires that the interface be fully resolved. While this is possible for some lower pressure GDI sprays, the high Reynolds and Weber numbers present in most diesel and some GDI sprays render this approach extremely expensive. Furthermore, the expense is compounded significantly in flash-boiling conditions where very small bubbles can be present within the spray itself, rendering the interface extremely complex. Second, this approach is inappropriate altogether when a sharp interface is not physically present, for instance in diesel sprays which can be near-supercritical $[10,11]$.

Alternatively, the diffuse interface approach attempts to model the behavior of the interface rather than resolve it. These types of models have been extremely successful in simulating diesel sprays $[44,29,50,13,36,17,12]$, and recently they have been applied to GDI sprays by Moulai et al. [23], Saha et al. [35, 34], and Strek et al. [43]. These four works all similarly modeled GDI internal nozzle flow and near field flashing and non-flashing sprays through the spray G Engine Combustion Network (ECN) injector. Additionally, all four works modeled vapor generation using the homogeneous relaxation model (HRM). The work of Moulai et al. showed that the counterbore experiences a pressure depression which may aid in expanding the fuel vapor. The 2015 work of Saha et al. [35] suggested that the nozzle asymmetry results in hole-to-hole variation in mass flow rate, and the 2016 work of Saha et al. [34] conducted static simulations at various needle lifts showing that the needle lift significantly affects the flow patterns. The work of Strek et al. used high fidelity X-ray tomography measurements to modify the inlet corner radius, hole and counterbore length, diameter, and convergence/divergence. Hole-to-hole mass flow rate and density profiles were then compared with X-ray tomography data to investigate the influence of manufacturing imperfections on GDI sprays. It should be noted that the solver used by Saha et al. is formulated like a sharp interface VOF model, however, in their works they deactivated the piecewise-linear interface calculation and high-resolution interface capturing schemes, and thus rendered it a diffuse interface model.

The same Eulerian solver used in the study conducted by Saha et al. was used by Battistoni et al. to studied the effect of off-axis needle motion on diesel DI injectors [4]. Here they found that off-axis needle motion affects hole-to-hole variation in mass flow rate as well as flow characteristics in the sac region and the nozzle orifices. Cavitation on the inlet corners was pre- 
dicted as was occasional string cavitation in the center of swirling flow in the nozzle holes.

\subsection{Present contribution}

In the present work a computational study was performed to investigate the influence of transient needle motion on internal nozzle flow and near-nozzle sprays for gasoline direct injection. This is a novel study in the application of GDI where the nozzle geometry, injection characteristics, fuel properties, and needle motion all differ significantly from diesel injection. Both flashing and non-flashing conditions are simulated. Grid resolution within the nozzle holes and sac of the injector is significantly higher in this study than in the previous diffuse interface GDI studies mentioned above. This has allowed for excellent qualitative agreement with experimental imaging and quantitative agreement with experimental rate of injection, and it has elucidated the complex internal flow which is behind perturbations and oscillations in spray angle and mass flow rate.

\section{Model Description}

The solver used in this study was developed at the University of Massachusetts $[18,38,27,25,26]$ using the foam-extend community driven extension of the OpenFOAM [47] CFD libraries. The use of these libraries provides a well-parallelized code with intrinsic polyhedral mesh support, as well as access to a wide variety of RANS and LES turbulence models and a multitude of pre and post processing utilities. The code has been well validated in many prior publications in applications ranging from channel flow [38], condensing two-phase injector flow [9], cavitating diesel flows [16], and flash-boiling GDI flow [23, 43].

The governing equations of conservation of mass and momentum are solved using a single continuous velocity which represents the density averaged fields.

$$
\begin{aligned}
\frac{\partial \rho}{\partial t}+\nabla \cdot \phi & =0 \\
\frac{\partial \rho \vec{U}}{\partial t}+\nabla \cdot(\phi \vec{U}) & =-\nabla p+\nabla \overline{\bar{\tau}}
\end{aligned}
$$

Here $\phi$ is the face valued mass flux and $\overline{\bar{\tau}}$ is the stress tensor accounting for viscous and turbulent effects. 
A transport equation for the mean non-condensable gas mass fraction is solved to account for the mixing of the fuel with the ambient gas. This is seen in Eqn. (4).

$$
\frac{\partial \rho \tilde{Y}}{\partial t}+\nabla \cdot(\phi \tilde{Y})=\nabla \cdot\left(\rho \widetilde{u^{\prime} Y^{\prime}}\right)
$$

The turbulent diffusion gas flux term, $\widetilde{u^{\prime} Y^{\prime}}$, accounts for the mixing effect of the relative velocity between the two phases. This term is closed through Fick's law of diffusion, as shown in Eqn. (5).

$$
\rho \widetilde{u^{\prime} Y^{\prime}}=\frac{\mu_{t}}{S c_{r}} \nabla \tilde{Y}
$$

Here $\mu_{t}$ is the turbulent viscosity, and $S c_{r}$ is the realizable Schmidt number field. This field acts in the place of the typical uniform valued Schmidt number of 0.9 , increasing wherever necessary to prevent the turbulent diffusion gas flux term from exceeding the magnitude of the turbulent velocity fluctuations. This formulation is described in detail here [12].

The phase change of the fuel is modeled using a method developed in 1990 by Bilicki and Kestin [7]. In this work they sought to capture the onedimensional variability in the vapor generation and condensation rate by the addition of a partial differential equation to the homogeneous equilibrium model (HEM), calling it the homogeneous relaxation model. This additional partial differential equation governs the local and instantaneous rate that the dryness fraction tends toward its equilibrium value, taking the form,

$$
\frac{D x}{D t}=\frac{\bar{x}-x}{\Theta}
$$

where $x$ is the quality, $\bar{x}$ is the equilibrium quality, and $\Theta$ is the timescale. The equilibrium quality is determined by the local enthalpy and pressure using a lookup Table generated with the REFPROP database [21].

The timescale, $\Theta$, is determined by an empirical fit to experimental data of flash-boiling water in pipes generated by Downar-Zapolski et al. [14]. For upstream pressures above $1 \mathrm{MPa}$, the empirical fit takes the form seen in Eqn. (7).

$$
\Theta=\Theta_{0} \alpha^{a} \phi^{b}
$$

Where $\Theta_{0}=3.84 \cdot 10^{-7}[\mathrm{~s}], \alpha$ is the fuel void fraction, $a=-0.54, b=-1.76$, and $\phi$ is a dimensionless pressure defined by Eqn. (8).

$$
\phi=\left|\frac{p_{\text {sat }}-p}{p_{c}-p_{\text {sat }}}\right|
$$


Here $p_{c}$ is the critical pressure of the fluid.

While HRM was originally developed for one dimensional analysis, it was extended to a two-dimensional CFD model in 1999 by Schmidt [37]. In 2010 it was extended to a three-dimensional CFD model by Schmidt et al. [38]. The introduction of variable rate phase change required a method for connecting predicted phase change with conservation of mass and momentum; in the present work the chain rule was used in the form seen in Eqn. (9). This allows for the pressure to respond to both compressibility, density change from phase change, and density change from turbulent mixing with the noncondensable gas.

$$
\begin{aligned}
\frac{D \rho}{D t} & =\left.\frac{\partial \rho}{\partial p}\right|_{x, h, y} \frac{D p}{D t}+\left.\frac{\partial \rho}{\partial x}\right|_{p, h, y} \frac{D x}{D t} \\
& +\left.\frac{\partial \rho}{\partial h}\right|_{p, x, y} \frac{D h}{D t}+\left.\frac{\partial \rho}{\partial y}\right|_{p, h, x} \frac{D y}{D t}
\end{aligned}
$$

\section{Simulation Setup}

\subsection{Mesh}

The mesh used for these simulations was based upon the nominal geometry and contained a $9 \mathrm{~mm}$ diameter outlet plenum. This is an 8 hole SVCO injector with 5 needle-guides, resulting in geometry which is symmetric across the xz-plane as can be seen in Figure 1. The designed clearance between the needle and needle-guides is around $3 \mu \mathrm{m}$, however for this study the clearance has been expanded to $30 \mu \mathrm{m}$ to prevent the zero thickness cells which would result from the needle wobble. It is possible that this clearance may deviate from the nominal value, and this will be investigated in future work.

The total cell count was 1.44 million with a minimum cell size of 7 $\mu \mathrm{m}$. No grid independence study was conducted, however, the cell count is comparable to or higher than that of other diffuse interface simulations reported in literature $[35,34,23]$. Furthermore, the mesh is significantly better resolved within the sac and nozzle hole regions than these studies; the grid spacing is roughly $10 \mu \mathrm{m}$ and $7 \mu \mathrm{m}$ in the sac and nozzle holes respectively, compared with the $30 \mu \mathrm{m}$ and $15 \mu \mathrm{m}$ reported by Saha et. al. [34], and $40 \mu \mathrm{m}$ and $10 \mu \mathrm{m}$ reported by Moulai et. al. [23]. Both of these works conducted a rate of injection (ROI) based grid independence study. 

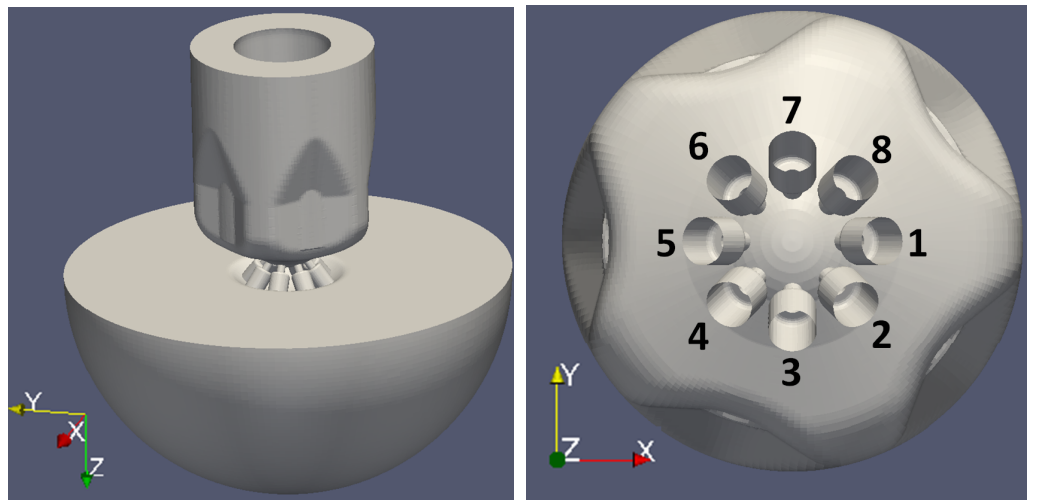

Figure 1: Nominal spray G nozzle geometry with 8 nozzle holes and 5 needle-guides. Simulated domain includes $9 \mathrm{~mm}$ diameter outlet plenum. Hole numbering and axes orientation based upon ECN convention [1].

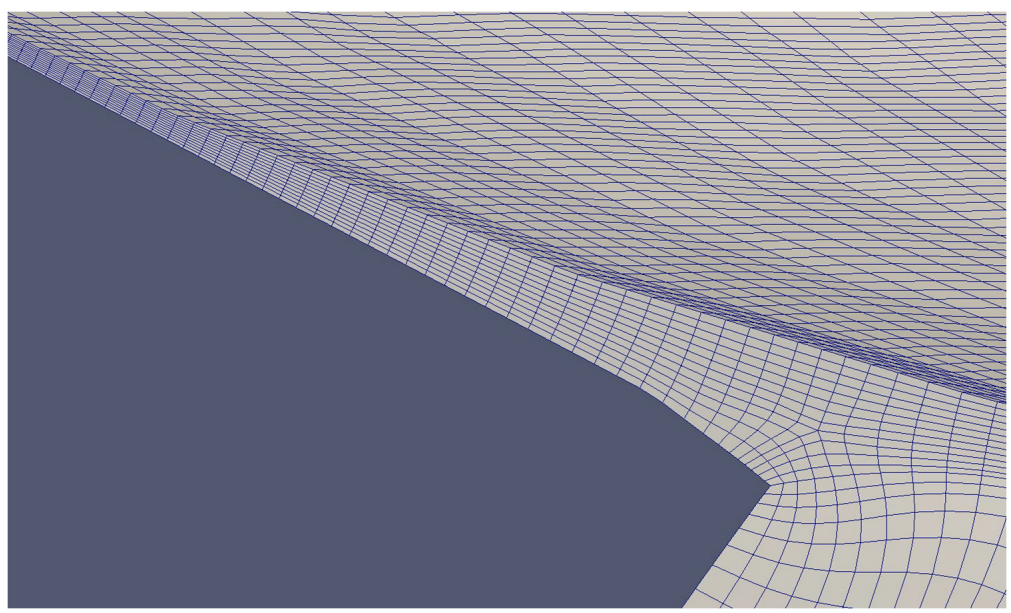

Figure 2: Cut plane of CFD mesh prior to needle lift. Anisotropic refinement can be seen in the narrow region between the needle and the nozzle.

The mesh was generated using GridPro meshing software which produced a high quality mesh and allowed for anisotropic refinement in the narrow 5 $\mu \mathrm{m}$ channel between the needle and the nozzle wall. This can be observed in Figure 2. Without anisotropic refinement, the cell count for this mesh would be closer to 18 million, with most of the cells located within the $5 \mu$ m narrow channel. 


\subsection{Needle motion}

A realistic three-dimensional needle motion profile has been applied in the simulations from measurements made via time-resolved X-ray phase contrast imaging. The experiments were conducted at the 32-ID beamline of the Advanced Photon Source (APS) at Argonne National Laboratory [40]. The injector was placed in a pressurized chamber fitted with X-ray transparent windows. A polychromatic X-ray beam was passed through the nozzle, and the internal components of the injector were imaged on a scintillator screen, which was recorded using a conventional high-speed camera and $10 \times$ microscope with a spatial resolution of $1.9 \mu \mathrm{m} /$ pixel and a temporal resolution of $8.33 \mu \mathrm{s}$. Further details regarding the experiment setup may be found in prior work $[19,33,15,46]$. The motion of the needle was recorded at two orientations of the injector in two regions at the front and back of the check ball, as shown in Figure 3. From 30 realizations of the needle motion at each location and orientation, the ensemble average three-dimensional motions were calculated using an image correlation algorithm.

The ensemble average needle lift and off-axis wobble profiles are shown in Figures 4-5 respectively, using the ECN coordinate convention [1]. It can be

seen that the needle wobbles in both the $\mathrm{x}$ and $\mathrm{y}$ directions, and at the same frequency. Analysis of the individual wobble profiles suggests that this may be occuring because the needle is influenced by fluid-structure interactions or that it may be physically contacting the needle guides. Due to the small magnitude of the wobble, the uncertainty in these measurements is relatively large. Further investigation is required to understand the physical mechanism of the wobble. Regardless, this wobble motion is fundamentally different from what is observed in diesel injectors, where the wobble is purely mechanical oscillation [22], and wobble velocity and magnitude are significantly greater.

Since the simulations require a finite positive initial needle lift, the motion used in the simulations was modified accordingly. The needle position started at $5 \mu \mathrm{m}$ of lift and remained stationary until $14 \mu \mathrm{s}$ into the simulation. The time of $14 \mu \mathrm{s}$ was chosen because this was the amount of time the experimental data indicated it would take to reach $5 \mu \mathrm{m}$ of lift. After this point, the needle position followed the experimental lift and wobble profile generated by the experiment. The internal mesh moved with Laplacian smoothing. To isolate the effects of the needle wobble, simulations were also done only with lift. 


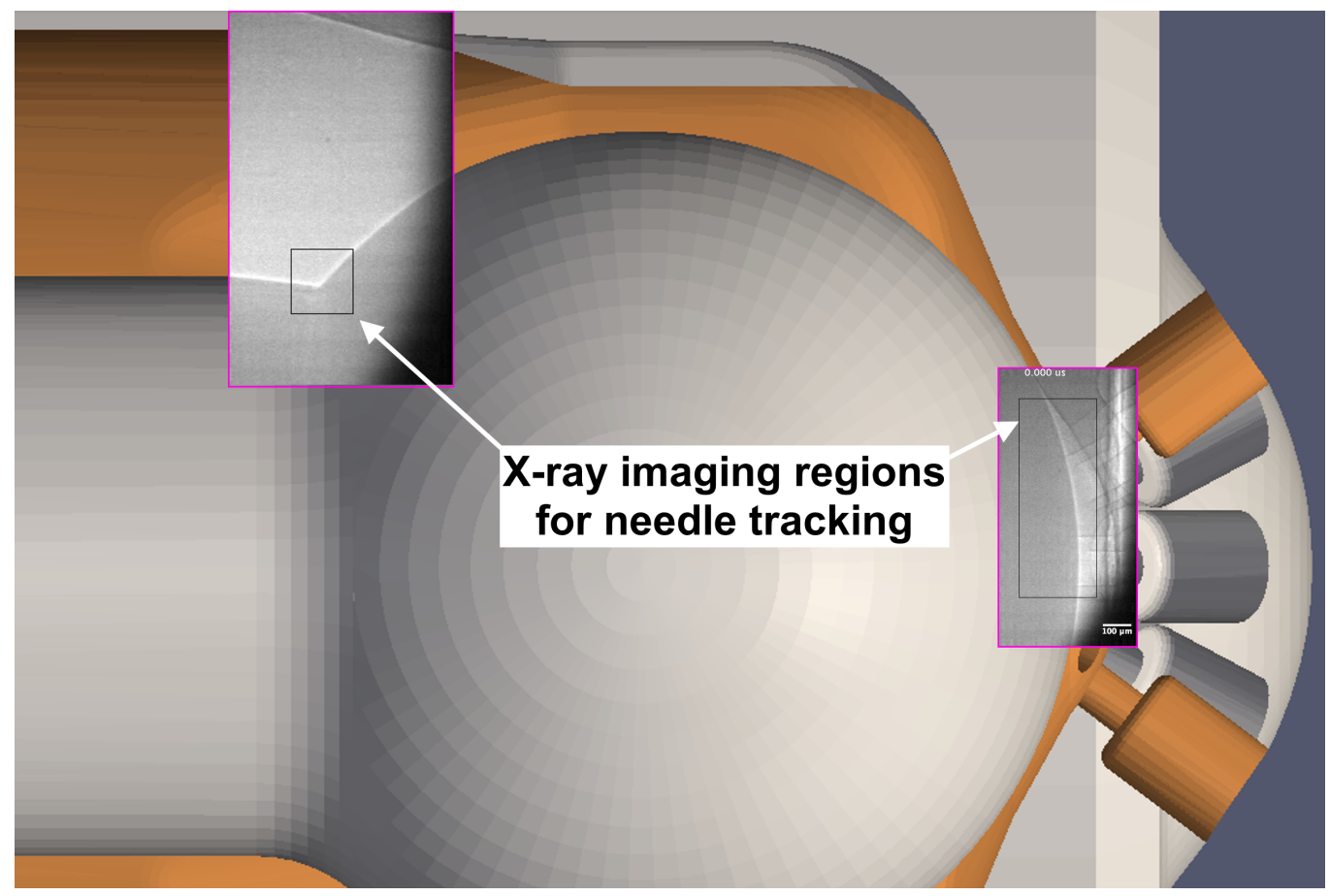

Figure 3: Cutaway of Spray G injector nominal geometry, with X-ray imaging regions overlaid.

\subsection{Initial and boundary conditions}

The simulations conducted for this study were based upon the engine combustion network (ECN) spray G and spray G2 operating conditions described in Table 1. The spray G condition is non-flashing due to its elevated back pressure and the spray G2 is mildly flashing.

The inlet boundary was modeled using a zero gradient boundary condition for velocity and a total pressure boundary condition for pressure. The outlet was modeled as zero gradient for velocity and an in-house transonic total pressure condition was used for pressure. Because the outlet velocities can be supersonic, a total pressure boundary condition is not appropriate. The transonic total pressure condition smoothly transitions from total pressure to zero gradient depending on the Mach number. This boundary condition increased the stability of the simulations.

As seen in Figure 6, the internal pressure field was initialized using a hyperbolic tangent to drop the pressure in the seat region. The internal field 


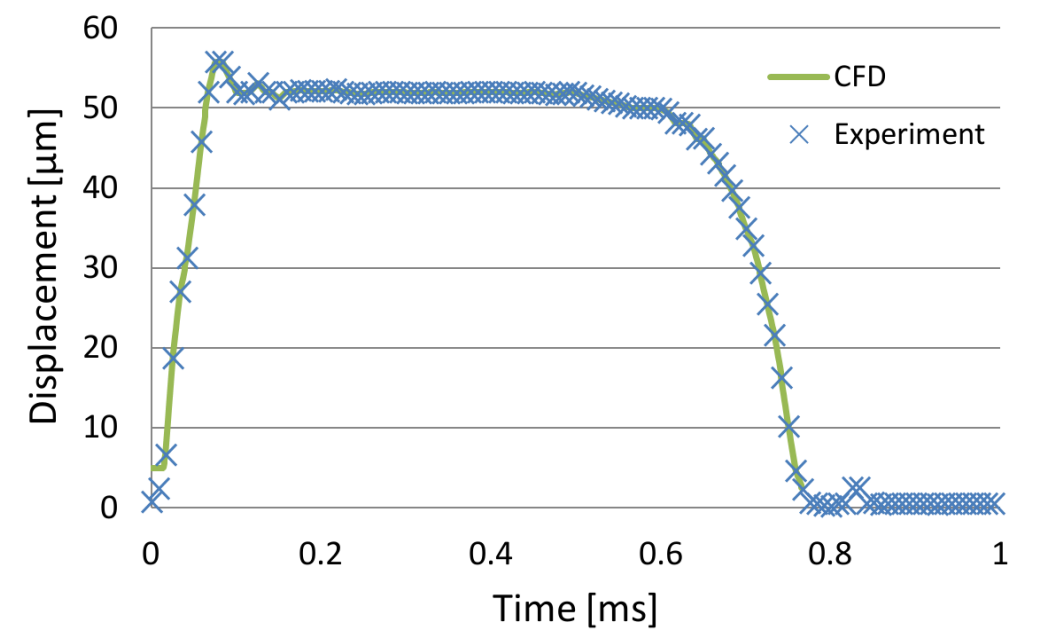

Figure 4: Ensemble-averaged needle lift ( $z$-axis) profile from the X-ray data (blue Xs) and the lift profile used in the CFD simulations (green line). Notice that the CFD profile starts at $5 \mu \mathrm{m}$ of lift.

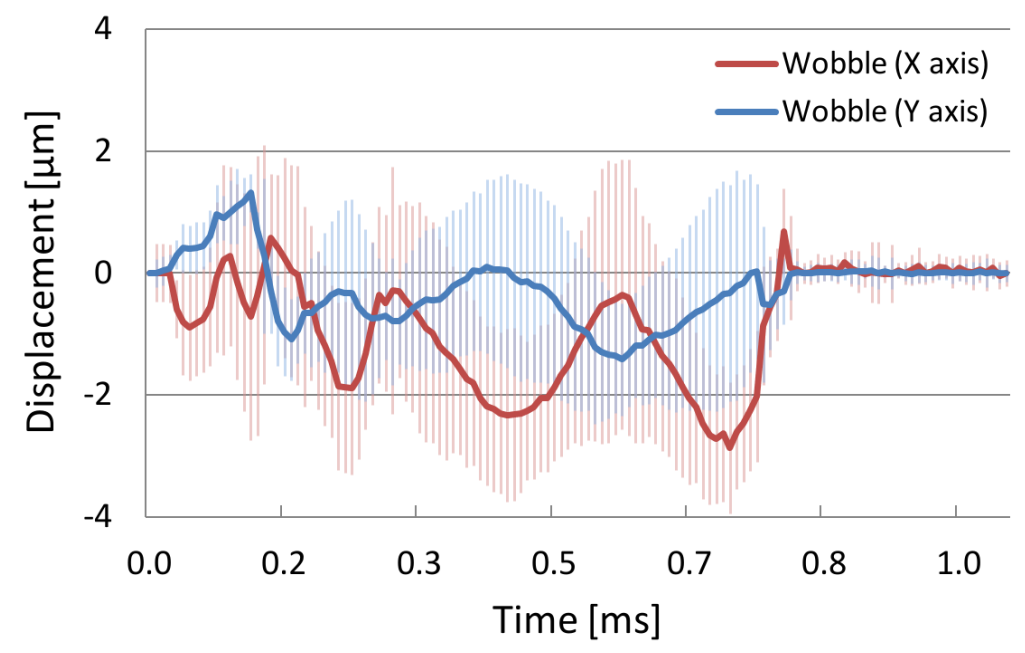

Figure 5: Ensemble-averaged needle wobble profile with $86 \%$ confidence interval bars.

for the non-condensable gas to fuel interface was set at the plane of minimum needle clearance.

Setting the internal fields in this way prevents spurious pressure waves from dominating the beginning portion of the simulation. It also allows for 
Table 1: Non-flashing (spray G) and Flashing (spray G2) operating conditions defined by the ECN [1].

\begin{tabular}{|c|c|c|}
\hline & Spray G & Spray G2 \\
\hline Fuel & Iso-octane & Iso-octane \\
\hline Upstream Pressure & $20 \mathrm{MPa}$ & $20 \mathrm{MPa}$ \\
\hline Fuel Temperature & $90^{\circ} \mathrm{C}$ & $90^{\circ} \mathrm{C}$ \\
\hline Ambient Temperature & $300^{\circ} \mathrm{C}$ & $60^{\circ} \mathrm{C}$ \\
\hline Ambient Density & $3.5 \mathrm{~kg} / \mathrm{m}^{3}$ & $0.5 \mathrm{~kg} / \mathrm{m}^{3}$ \\
\hline Back Pressure & $600 \mathrm{kPa}$ & $50 \mathrm{kPa}$ \\
\hline Injection Duration & $780 \mu \mathrm{s}$ & $780 \mu \mathrm{s}$ \\
\hline
\end{tabular}

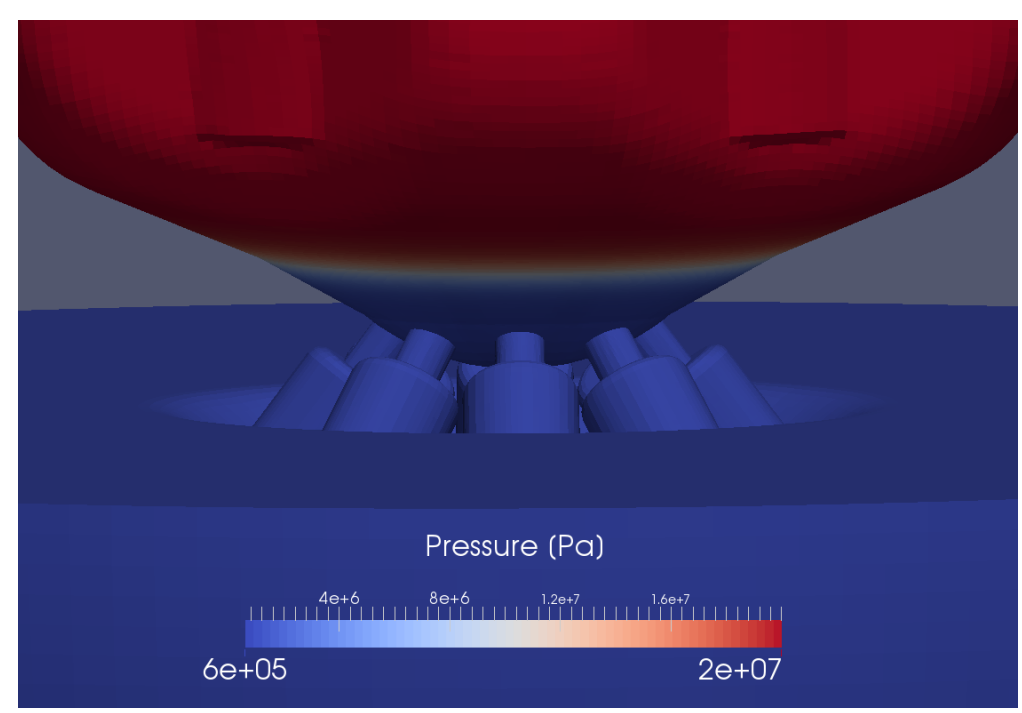

Figure 6: Pressure initial condition set with hyperbolic tangent.

the initial density field to be calculated appropriately, so that the fuel begins with its compressed density of $646 \mathrm{~kg} / \mathrm{m}^{3}$. A comparable simulation which starts with the downstream pressure throughout the domain would result in an initial equilibrium fuel density of $632 \mathrm{~kg} / \mathrm{m}^{3}$, and much of the simulation would include unwanted effects related to the solver working to compress the upstream fuel. 


\subsection{Turbulence closure and model assumptions}

Turbulence was modeled using the SST k- $\omega$ RANS model. This model is known to perform well in adverse pressure gradients and separating flow. Standard log-layer wall functions were used at the wall.

Compressibility of the fluid was a volume weighted average of the compressibility of the three phases, where gas and vapor compressibility were based upon the ideal gas law, and liquid compressibility was assumed to be linear.

The simulation was assumed to be isenthalpic. Throttling processes are often considered isenthalpic, since no work is done by the fluid.

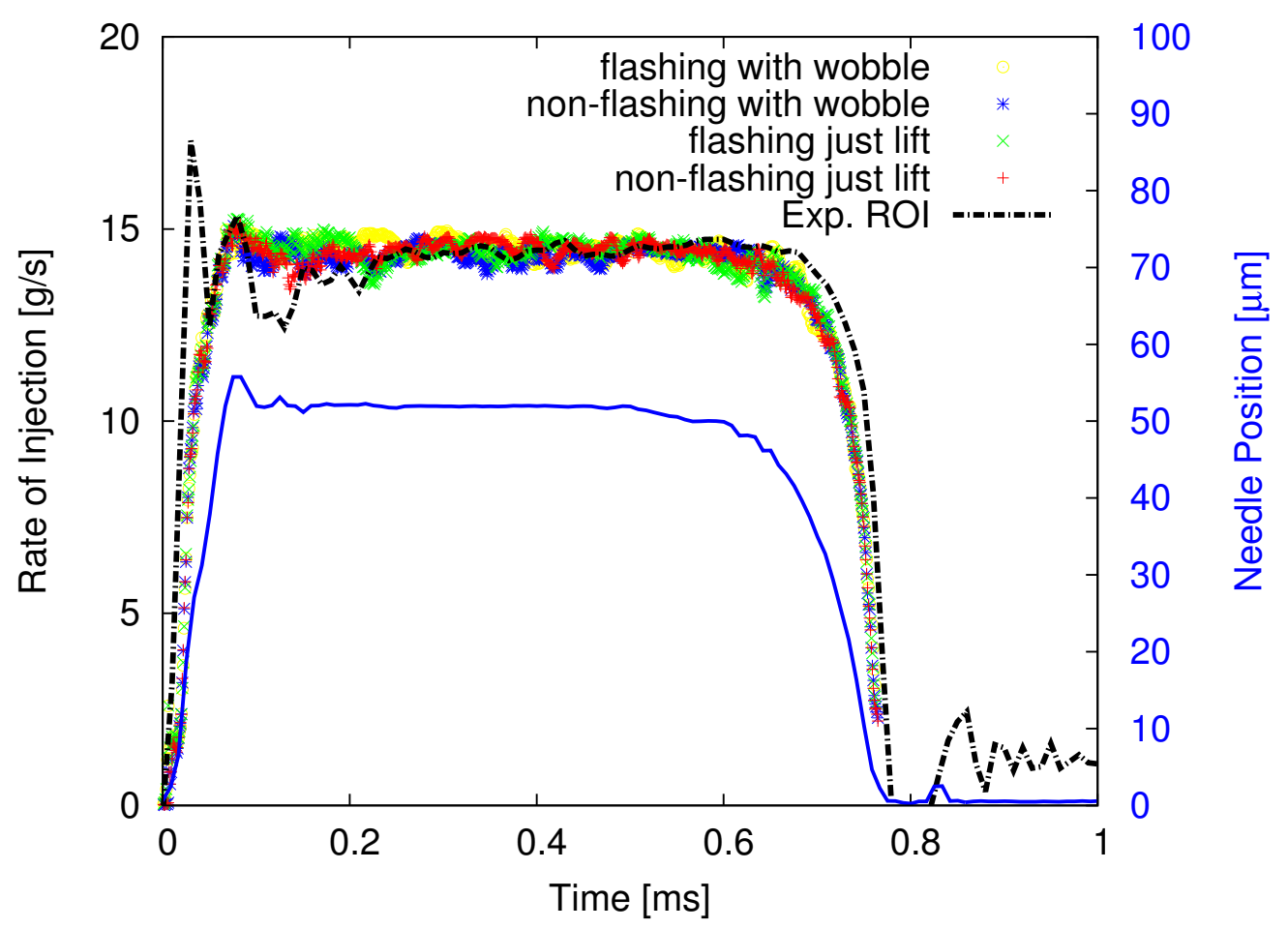

Figure 7: Simulated and experimental ROI with needle position vs. time. Experimental ROI obtained through the long-tube method and simulation ROI taken at the nozzle exit. 


\section{Results}

\subsection{Rate of injection}

ROI profiles were generated for all four cases by integrating the mass flux across the outlet of the injector. These profiles were compared with experimental ROI measurements taken through the long-tube method. These data, in addition to the needle lift profile can be seen in Figure 7. Excellent agreement was observed between the simulation ROI profiles and experimental measurements and several interesting observations have been made.

First, in the early portion of the injection the experimental ROI profile is significantly more noisy than the profiles generated from the simulations. Such noise is commonly observed in ROI profiles generated through the longtube method. It has previously been suggested that this noise does not represent actual fluctuations in the ROI, rather that the noise is due to vibrations in the experimental rig [22]. Our simulation results support this conclusion.

Next, the simulation ROI profiles follow the needle lift profile, even responding to the transient overshoot which occurs just as the needle reaches peak lift. The response to needle lift in the experimental profile is not as pronounced. This is partially due to the previously mentioned noise, but it is also a consequence of the measurement occuring some distance downstream of the injector in the long-tube method.

Finally, fluctuations of similar magnitude and frequency are observed in all ROI profiles. Analysis of the CFD results reveals that these fluctuations are primarily a result of fuel vapor in the nozzle holes restricting the available exit area, as seen in Figures 17 and 20 and described in section 4.6.

These results provide a quantitative validation of the simulations. They also provide insight into the ROI during the transient start of injection period which is difficult to obtain experimentally. Finally, they show that an accurate ROI profile can be obtained through CFD simulations using total pressure boundary conditions and transient needle lift to actuate injection.

\subsection{Total injected mass}

Total injected mass data was obtained by integrating the mass flux throughout the duration of the injection across the outlet of each nozzle hole. This yielded the data seen in Table 2 . Results agree well with the $10 \mathrm{mg}$ injected mass target specified by the ECN [1]. The hole-to-hole variation in total injected mass is small; on the order of $1-2 \%$. No apparent dependence on the 
Table 2: Total injected mass for the four CFD cases. Data are colored by magnitude.

\begin{tabular}{|c|c|c|c|c|}
\hline & $\begin{array}{c}\text { Spray G Just } \\
\text { Lift [mg] }\end{array}$ & $\begin{array}{c}\text { Spray G w/ } \\
\text { Wobble [mg] }\end{array}$ & $\begin{array}{c}\text { Spray G2 Just } \\
\text { Lift [mg] }\end{array}$ & $\begin{array}{c}\text { Spray G2 w/ } \\
\text { Wobble [mg] }\end{array}$ \\
\hline Hole 1 & 1.29 & 1.30 & 1.28 & 1.29 \\
\hline Hole 2 & 1.25 & 1.25 & 1.31 & 1.27 \\
\hline Hole 3 & 1.26 & 1.25 & 1.29 & 1.28 \\
\hline Hole 4 & 1.29 & 1.27 & 1.27 & 1.29 \\
\hline Hole 5 & 1.27 & 1.29 & 1.25 & 1.31 \\
\hline Hole 6 & 1.27 & 1.27 & 1.28 & 1.29 \\
\hline Hole 7 & 1.29 & 1.26 & 1.27 & 1.28 \\
\hline Hole 8 & 1.32 & 1.29 & 1.28 & 1.28 \\
\hline Total & 10.24 & 10.17 & 10.24 & 10.29 \\
\hline
\end{tabular}

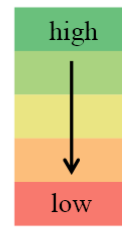

symmetry of the nozzle can be seen, indicating that the nozzle symmetry is of little importance and that any significant and consistent variation in holeto-hole injected mass observed experimentally is likely due to manufacturing imperfections in the nozzle. Finally, the needle wobble doesn't appear to influence the injected mass in a consistent way, an idea which will be explored in more detail in section 4.6.

\subsection{Qualitative validation}

The qualitative behavior of these simulations matches well with experiment in three ways.

First, the results for the non-flashing spray $\mathrm{G}$ condition predicted ingestion of ambient gas into the nozzle counter-bores. In contrast to this, no ingestion of ambient gas was predicted for the flashing spray G2 condition. This is due to flashing, expanding spray filling the counter-bore and preventing ambient gas ingestion. As seen in Figure 8, experimental imaging of flashing and non-flashing GDI injection has shown the same behavior. The flow pattern in these two conditions is fundamentally different. In nonflashing conditions, the ingestion of ambient gas effectively restricts the exit area of the counter-bore, producing narrower spray cone angles. Conversely, in flashing conditions, the exit area of the spray is restricted by the counterbore walls. This has interesting implications for the design of the nozzle, as the geometry is restricting the expansion of the flashing jet. Furthermore, the contact of the spray with the counter-bore walls is of particular inter- 


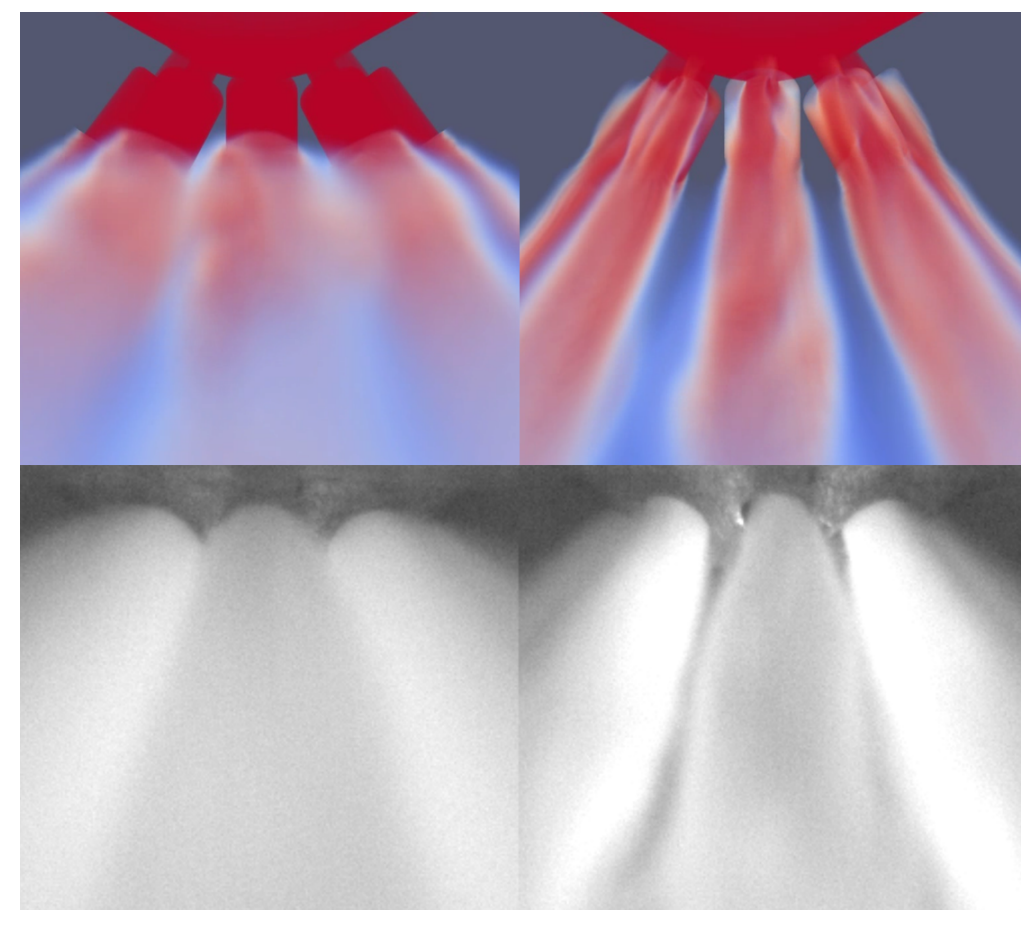

Figure 8: Flashing (left) and non-flashing (right) experimental images (bottom) and volume rendered fuel mass fraction from CFD (top) midway through injection. Uniform contact of fuel with counter-bore is seen under flashing conditions, while non-flashing shows gaps in contact allowing ingestion of ambient gas.

est as it can lead to tip wetting and, subsequently, increased emissions and carbon buildup on the injector walls [6].

Next, our simulations predicted an expansion and perturbation of the spray angle at the end of injection. This has been observed through experimental imaging as seen in Figure 9 where the liquid mass fraction is compared with experimental images in the non-flashing condition. Such a perturbation appears to also lead to tip wetting, and the ability to predict this undesirable behavior in CFD simulations could be a helpful tool for fuel injector design.

Finally, when comparing animations from the flashing and non-flashing simulation results to experimental footage, it was found that the frequency and magnitude of the oscillations in the spray plumes match very well. These oscillations in the spray plumes were found to be the result of unsteady flow within the sac influencing the flow characteristics within the 8 holes. This 

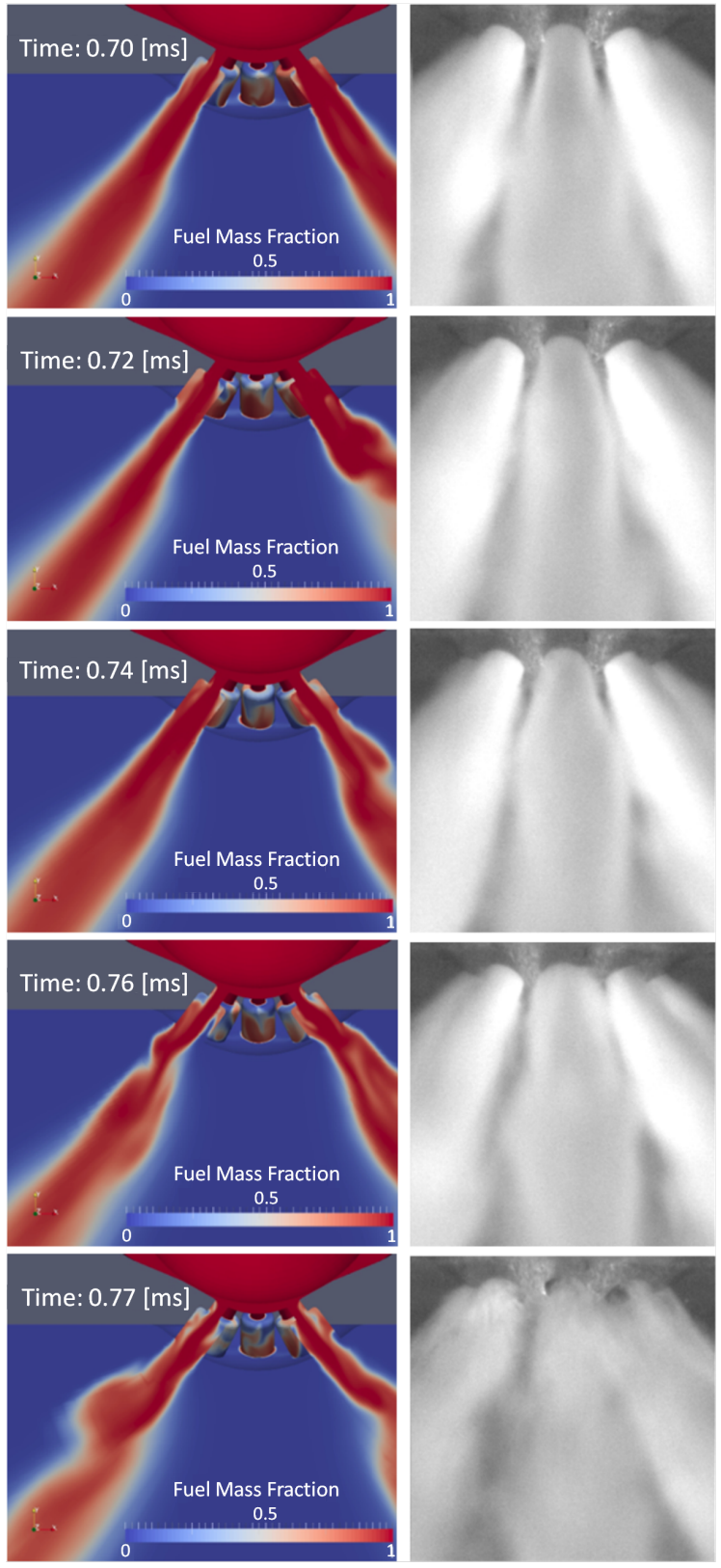

Figure 9: Simulated fuel mass fraction compared with experimental imaging at the end of non-flashing simulation. Note that the spray angle increases as flow is disrupted with the closing of the needle. 
conclusion will be described further in section 4.6.

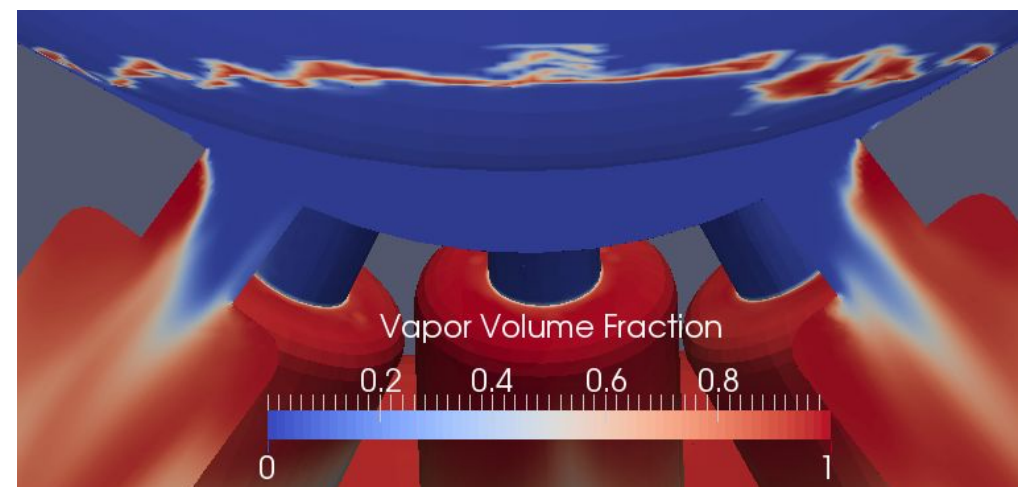

Figure 10: Vapor generated at low lift conditions near the end of injection, $0.765 \mathrm{~ms}$ after the start of injection in spray G2 simualtion.

\subsection{Flash-boiling at low lift conditions}

At low needle lift conditions at the end of injection, very low pressures occur within the injector in the narrow region between the needle and the nozzle wall. The pressure drop here is similar to what is seen in a convergentdivergent nozzle in subsonic or choked conditions. This low pressure causes fuel vapor to be generated as fuel rushes past the needle, as seen in Figure 10.

Vapor generation in this region may influence the post-injection condition of the sac, with the inevitable vapor collapse aiding in the ingestion of ambient gas. Furthermore, it is possible that cold fuel may cavitate in this region of the nozzle, potentially damaging the nozzle walls over time.

\subsection{Needle wobble}

Simulations were conducted with and without needle wobble to help isolate any influence the lateral motion of the needle may have had on the spray. While the hole-to-hole variation in mass flow rate did differ from case to case, the variations could not be tied to the needle wobble. A description of the analysis used to reach this conclusion follows.

In order to compare the motion of the needle wobble to the variations in mass flow rate, the center of mass flow was calculated on a set of faces which 


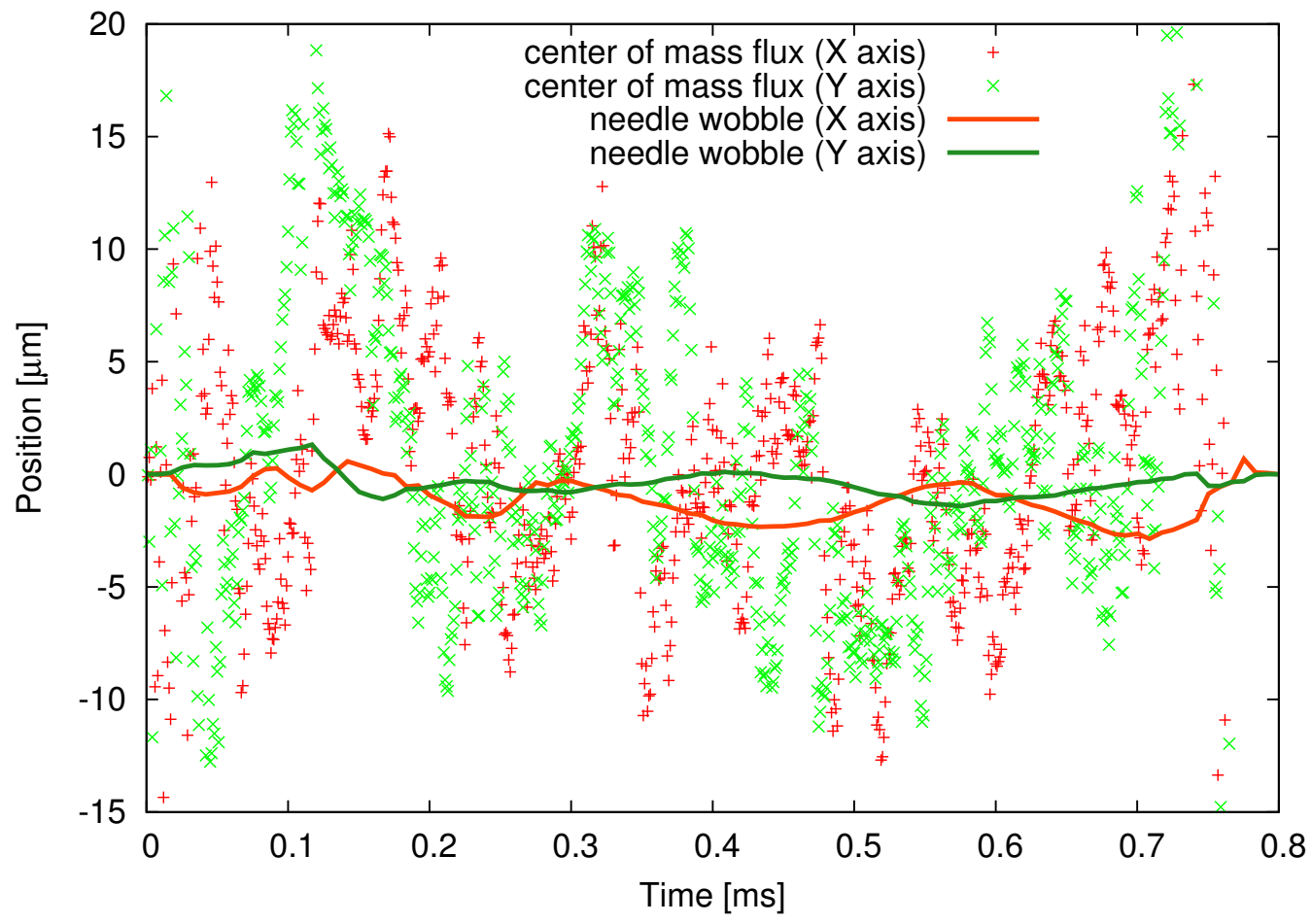

Figure 11: Center of mass flow and needle wobble plotted over time for the spray G with wobble simulation.

perpendicularly cut through the middle of each of the 8 nozzle holes. This calculation was done with the two surface integrals shown in Eqn 10.

$$
\text { center of mass flow }=\frac{\text { first moment of mass flow rate }}{\text { mass flow rate }}=\frac{\iint_{S} \phi x_{i} d S}{\iint_{S} \phi d S}
$$

The center of mass flow rate among the 8 nozzle holes is plotted with the needle wobble in Figure 11. Here it can be seen that the magnitude of the variation in the hole-to-hole mass flow rate far exceeds the magnitude of the needle wobble. Additionally, no significant correlation between the two paths could be found.

This was a somewhat unexpected result as previous works have shown that needle wobble can influence spray structure and mass flow rate in diesel injectors [4]. It is not, however, unexplainable as the spray G geometry differs significantly from that of a diesel injector. First of all, the magnitudes of the 
lift and wobble in GDI injectors are significantly less than in diesel injectors. This means that needle velocities are lower, with a peak wobble velocity of less than $0.2 \mathrm{~m} / \mathrm{s}$ in this case. Next, the needle has a spherical tip. This means that the bottom portion of the needle surface is close to parallel to any wobble motion, and thus wobble does not displace any significant volume of fluid in the nozzle sac. Finally, the magnitude of the wobble is small, around $3 \mu \mathrm{m}$. This small and slow wobble results in its most significant displacement of volume far upstream of the nozzle holes, and any influence this motion has on the flow is far overshadowed by the highly turbulent and complex flow which follows further downstream.

It should be noted that the full effect of the needle wobble in the needleguide region may not be felt in these simulations, as needle to needle-guide clearance has been expanded beyond the nominal clearance to prevent zero thickness cells. Without experimentally measuring the actual needle to needle-guide clearance, it is difficult to estimate the significance of the dynamics in this region.

\subsection{Complex internal flow}

As fuel moves past the needle it accelerates to roughly $140 \mathrm{~m} / \mathrm{s}$ at full needle lift and close to $250 \mathrm{~m} / \mathrm{s}$ at low lift. Upon reaching the location of the nozzle holes the fuel then either enters a nozzle hole or the nozzle sac. The viscous losses at this point are small, so the average static pressure in the center of the sac is close to the injection pressure, around $17 \mathrm{MPa}$. This means that the fuel entering the nozzle sac encounters a strong adverse pressure gradient. This adverse pressure gradient results in the generation of vortices and turbulence as the fuel contends for a path into one of the eight nozzle holes. Analysis of the simulation results reveals that these vortices are transient and interacting, resulting in a complex internal flow which produces hole-to-hole fluctuations in mass flow rate, slight oscillations and variation of the spray angle, consistent flash-boiling at the inlet corner of the nozzle holes, and intermittent string flash-boiling as vortices are entrained into the nozzle holes. Each of these features will be assessed in more detail within this section.

First, the inlet corners of each of the 8 nozzle holes consistently produces a sufficient pressure drop to generate substantial amounts of fuel vapor. As can be seen in Figure 12, this occurs on the upstream side of the nozzle holes. Here high velocity fuel encounters the hole and a huge pressure drop results as the momentum of the fuel prevents it from following the sharp feature. 


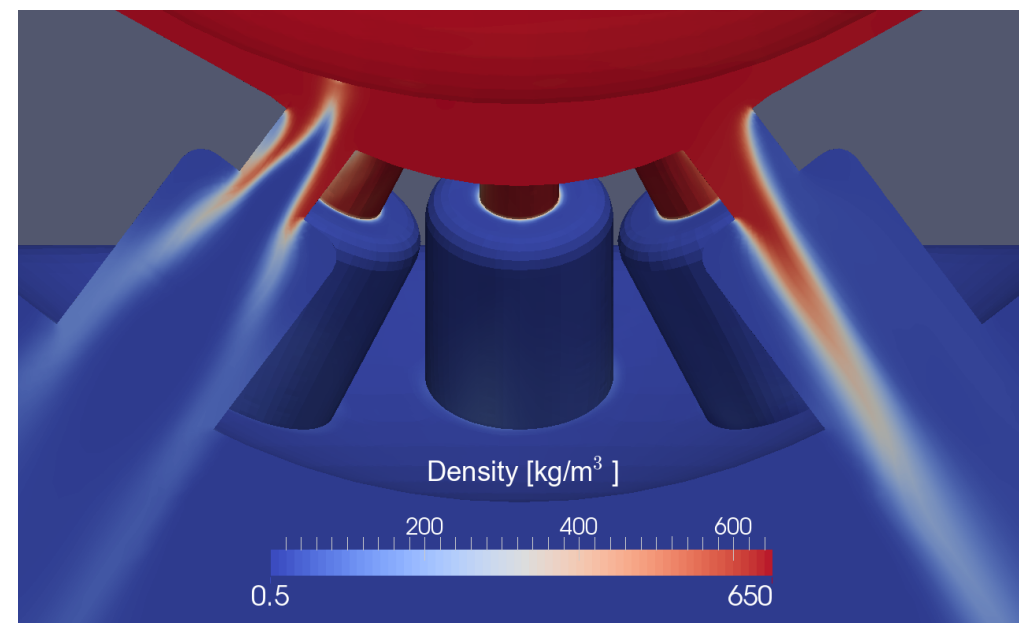

Figure 12: Density field $0.339 \mathrm{~ms}$ into simulation under flashing conditions. The influence of vapor generation at the inlet corner can be seen. The left nozzle hole is also generating vapor through string flash-boiling.

Vapor generation here is aided by the fact that this simulation was conducted on the nominal geometry which contains sharp inlet corners. The nozzle hole on the left of Figure 12 is also generating vapor through string flash-boiling, a phenomena which will be discussed in detail later in this section.

Next, the flow in the injector sac contains many transient and interacting vortices. These vortices are generated as high speed flow enters the sac from all directions and encounters a strong adverse pressure gradient. The low pressure regions of the nozzle holes continuously pull on the flow, inducing swirl and providing sinks into which the vortices drain. Three types of vortices were commonly observed in these simulations and can be seen with the aid of streamlines and isosurfaces of total pressure in Figures 13 through 15:

- Unterminated: A vortex which simultaneously drains into two adjacent nozzle holes. The streamlines on Figures 13 and 14 help show how this happens; the vortex is fed from the bottom by flow directly upstream of the vortex and fed from the top by sac flow. As the sac flow encounters upstream flow their momentum relative to the nozzle holes cancel out resulting in a vortex which then simultaneously drains into both holes. This type of vortex is semi-stable, typically lasting on the order of $10-20 \mu \mathrm{s}$. 


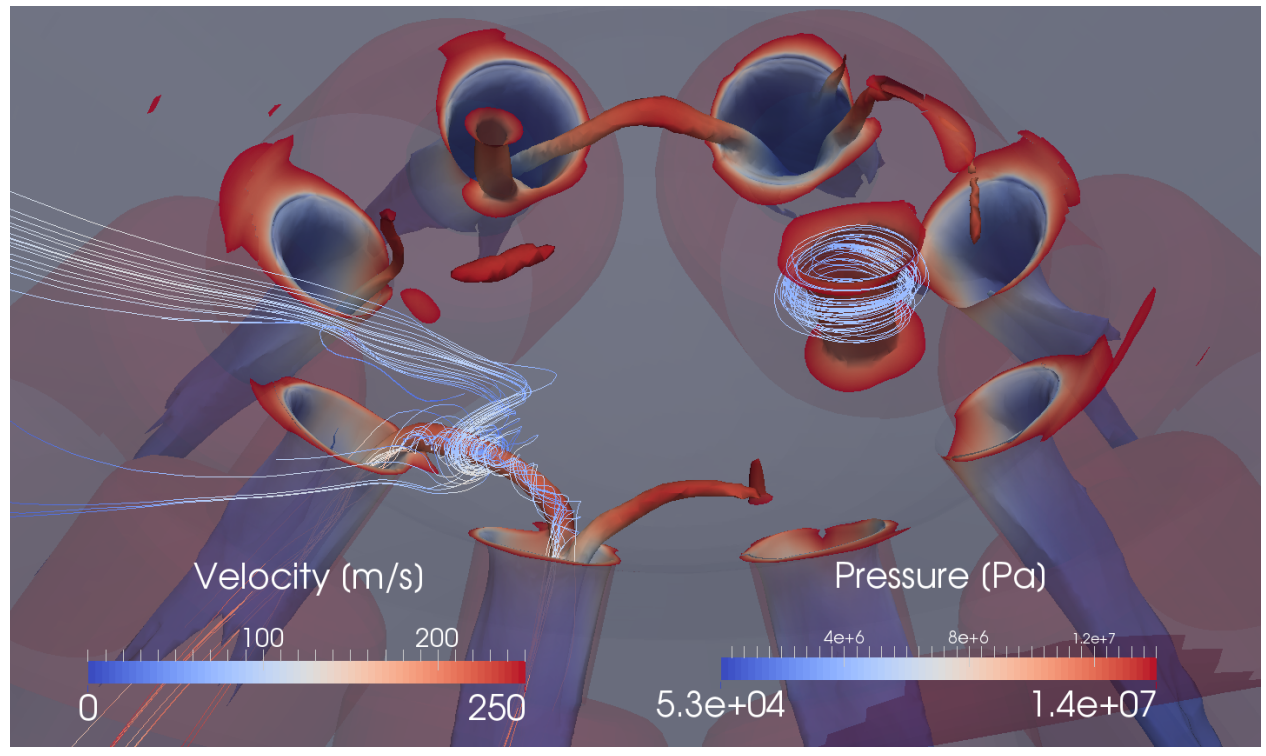

Figure 13: Isosurface of $14 \mathrm{MPa}$ total pressure colored by static pressure with velocity streamlines colored by velocity magnitude. Taken midway through flashing simulation. Vorticies contained in the sac can be seen to terminate on a wall or they can be entrained into one or two nozzle holes.

- Semi-terminated: A vortex which drains into a single nozzle hole, with the other end terminating on the needle of the injector. This is seen in Figure 15. These vortices are fed primarily by upstream flow and they are significantly more stable, lasting on the order of 40-80 $\mu \mathrm{s}$.

- Fully-terminated: A vortex which does not feed into a nozzle hole, terminating on the nozzle wall and the bottom of the needle. This can be seen in the right center of Figure 13. Such a vortex typically either dissipates within $5-10 \mu$ s or migrates to a nozzle hole and is re-energized.

The estimated timescales of these vortices were generated from animations of total pressure isosurfaces. It is common for vortices to move around, merge together, and/or split apart, thus transitioning sequentially from type to type.

The behavior of these vortices can be understood more with the help of examination of the helicity of the flow. Helicity is the dot product of the velocity with the vorticity. Thus, it is a signed scalar field which can be 


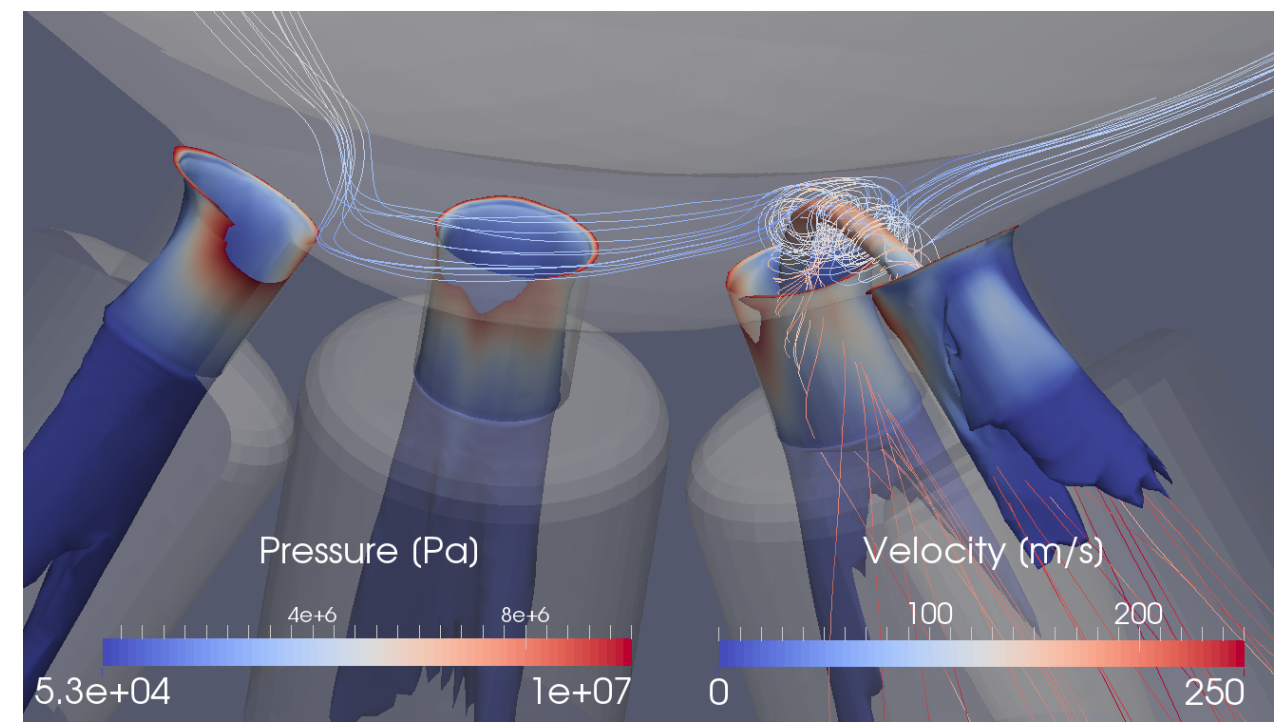

Figure 14: Isosurface of $10 \mathrm{MPa}$ total pressure colored by static pressure with velocity streamlines colored by velocity magnitude. Taken midway through flashing simulation.

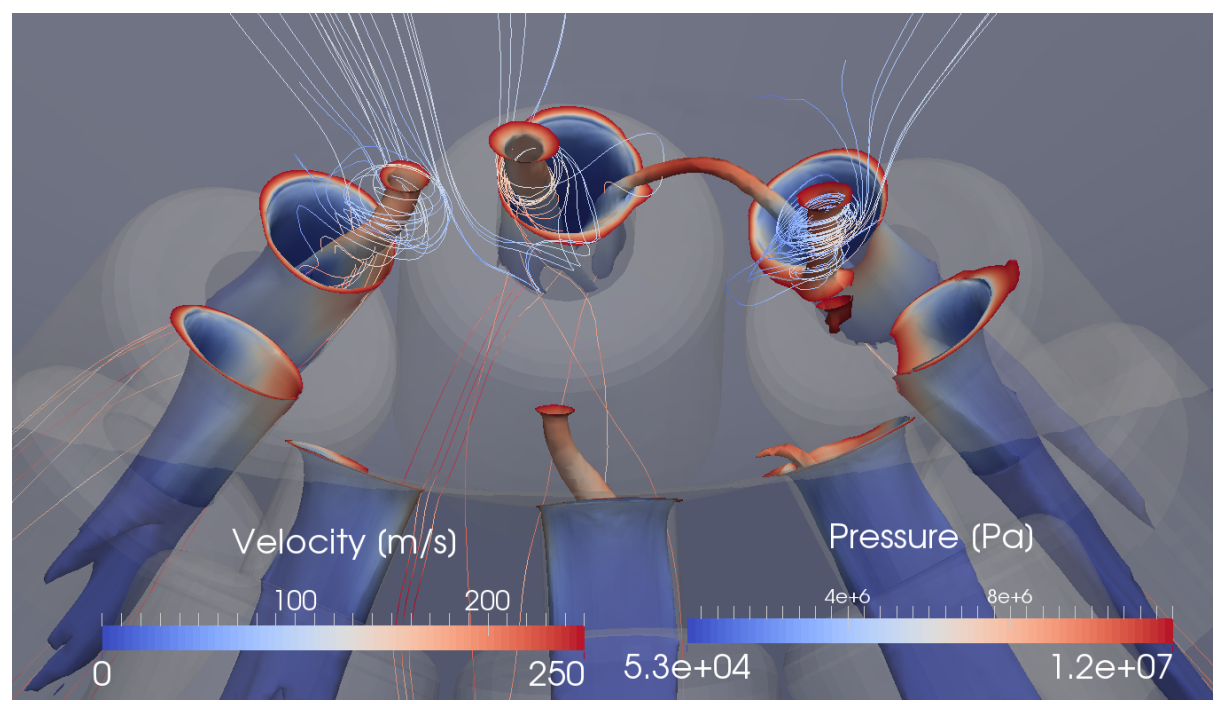

Figure 15: Isosurface of $12 \mathrm{MPa}$ total pressure colored by static pressure with velocity streamlines colored by velocity magnitude. Taken midway through flashing simulation. 


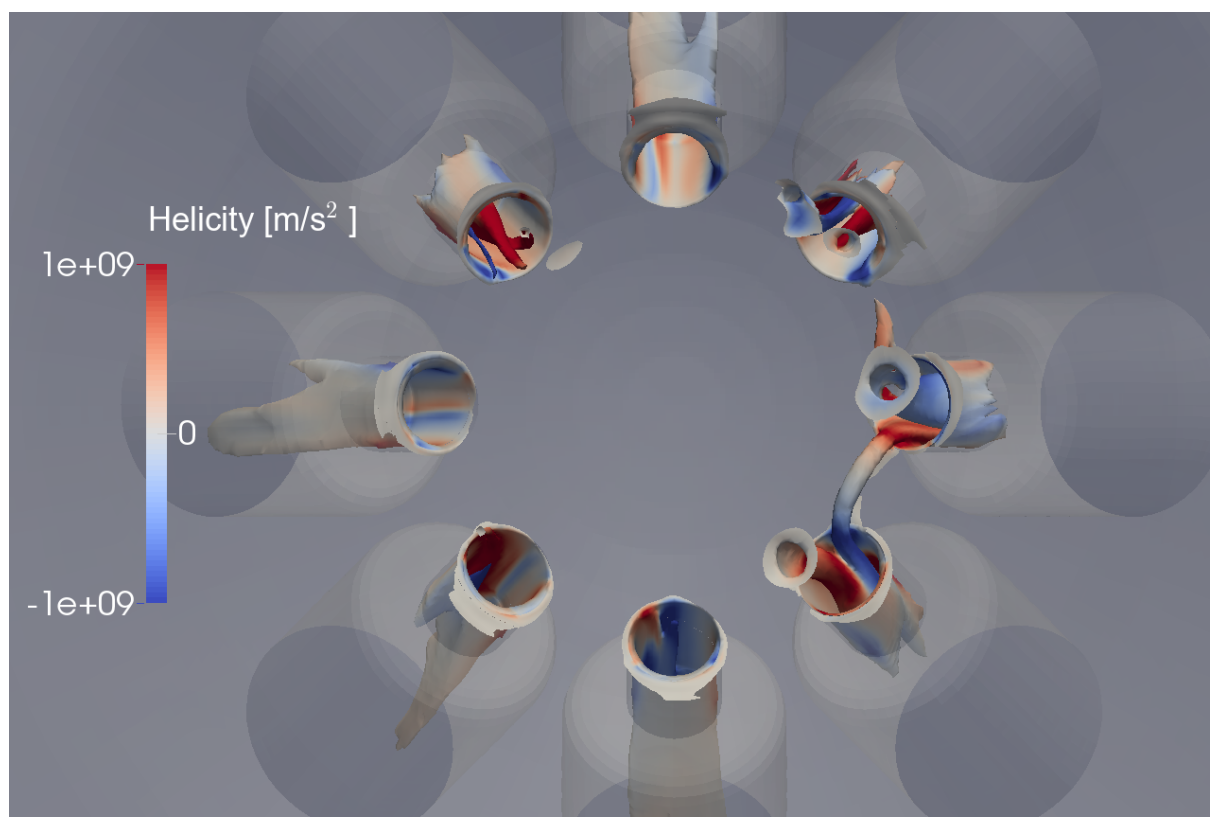

Figure 16: Isosurface of $14 \mathrm{MPa}$ total pressure colored by helicity. Note that counterrotating vortices often drain into the same nozzle hole. Taken midway through flashing simulation. 
useful in determining the direction of the flow rotation. As seen in Figure 16 , it is common for two counter-rotating vortices to drain into a single nozzle hole. Co-rotating vortices, on the other hand are unstable and tend to either merge together or break each other apart. To gain a sense of the magnitude of the helicity observed in these simulations, consider that the square of the characteristic velocity (volume flow rate / exit area) divided by the hole diameter is about $10^{8} \mathrm{~m} / \mathrm{s}^{2}$. This means that the helicity values are indeed quite strong relative to the mean flow, on the order of $+/-10$ compared to this characteristic normalizing value.

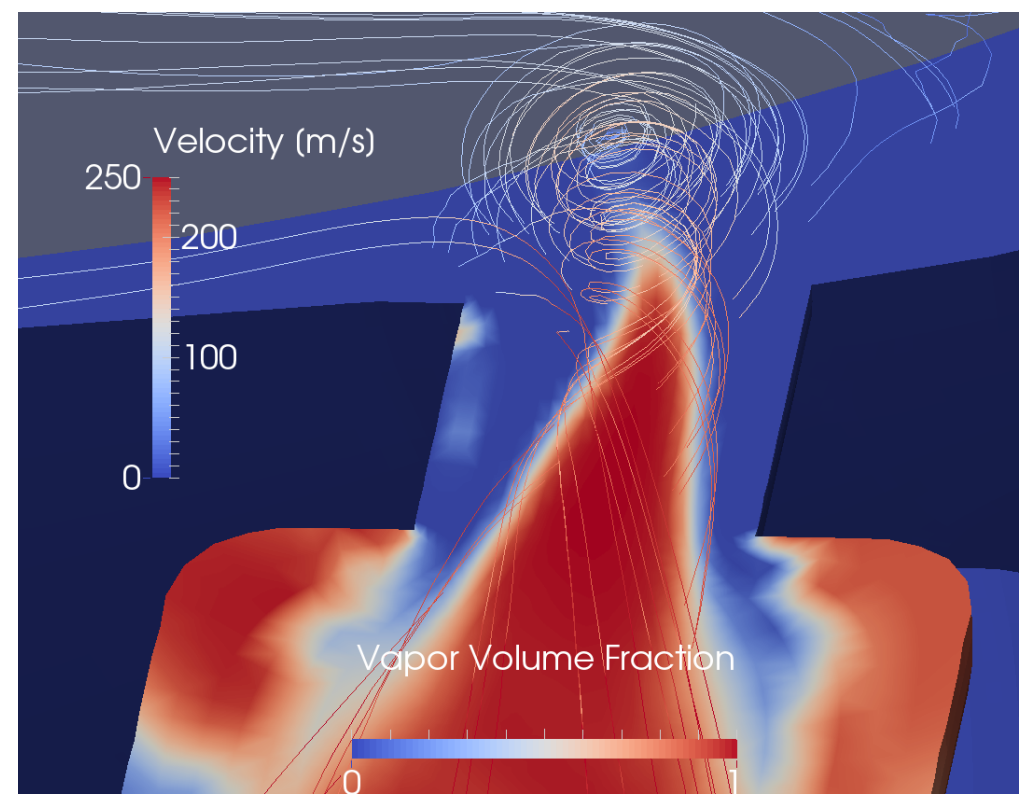

Figure 17: String flash boiling resulting from the swirling flow in the sac. Taken midway through flashing simulation. Streamlines are colored by velocity and the cut plane is colored by the vapor volume fraction.

As vortices are entrained into the nozzle holes, the simulation often predicts vapor generation at their core. A similar phenomena is commonly observed in other applications when strings of vapor are generated through cavitation. The vapor generation process here, however, is more appropriatly described as flash-boiling because the fuel is hot and this is a thermal non-equalibrium process. String flash-boiling can be seen in Figures 17 and 18 where a single vortex, or two counter-rotating vortices can result in a 

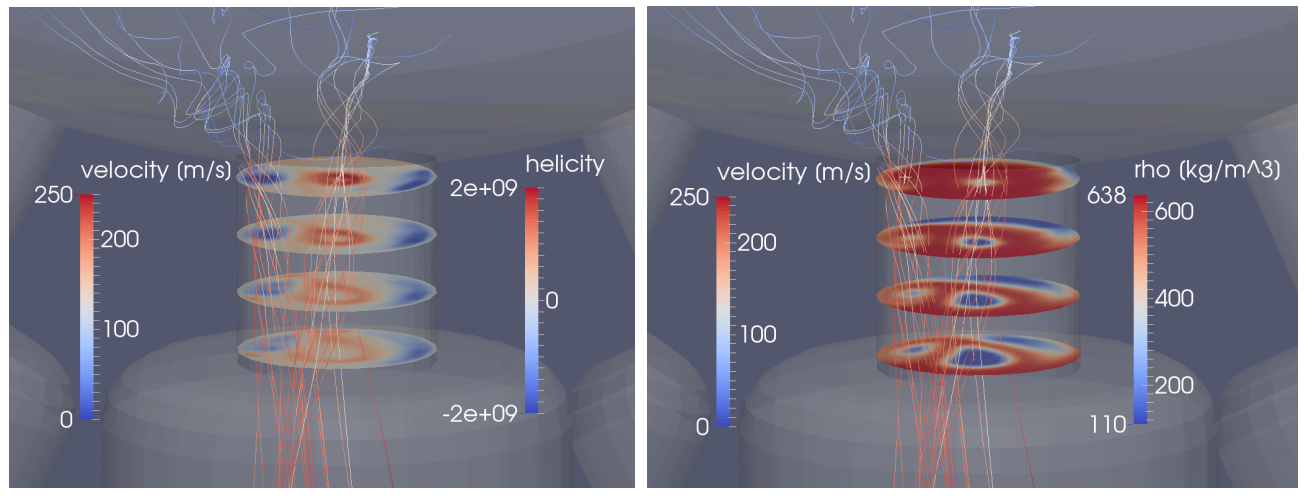

Figure 18: Two counter-rotating vortices being entrained into a single nozzle hole. Taken midway through non-flashing simulation. Streamlines are colored by velocity and the cut planes are colored by helicity on the left image and density on the right image.

significant drop in flow density.

While string flash-boiling is similarly observed in both the spray $G$ and spray G2 conditions, they behave differently in the near-field region. In the spray G2 condition, the lower back pressure allows for the vapor core to continue to expand in the near-field. In the spray $\mathrm{G}$ condition, the vapor collapses within and outside the counter-bore and is displaced by noncondensable gas.

The swirling nature of the flow also has an influence on the vapor generated at the inlet corner as seen in Figure 18. Here the vapor generated at the inlet corner appears to be both compressed and transported by the swirling flow.

This complex internal nozzle flow results in perturbations and expansions of the spray angle. Figure 19 shows the expansion of the spray angle caused by string flash-boiling. Here the nozzle hole on the left contains a large vortex and the hole on the right does not. Similar to a swirl atomizer, as the vortex exits the nozzle hole the angular momentum of the flow tears the jet apart. The counterbore walls then serve to geometrically restrict the expansion of the flow.

Finally, this complex internal nozzle flow also results in fluctuations in the mass flow rate. Mass flow rate and averaged density were calculated across a set of faces which perpendicularly cut through the middle of each of the 8 nozzle holes. These results are shown in Figure 20. The oscillations 


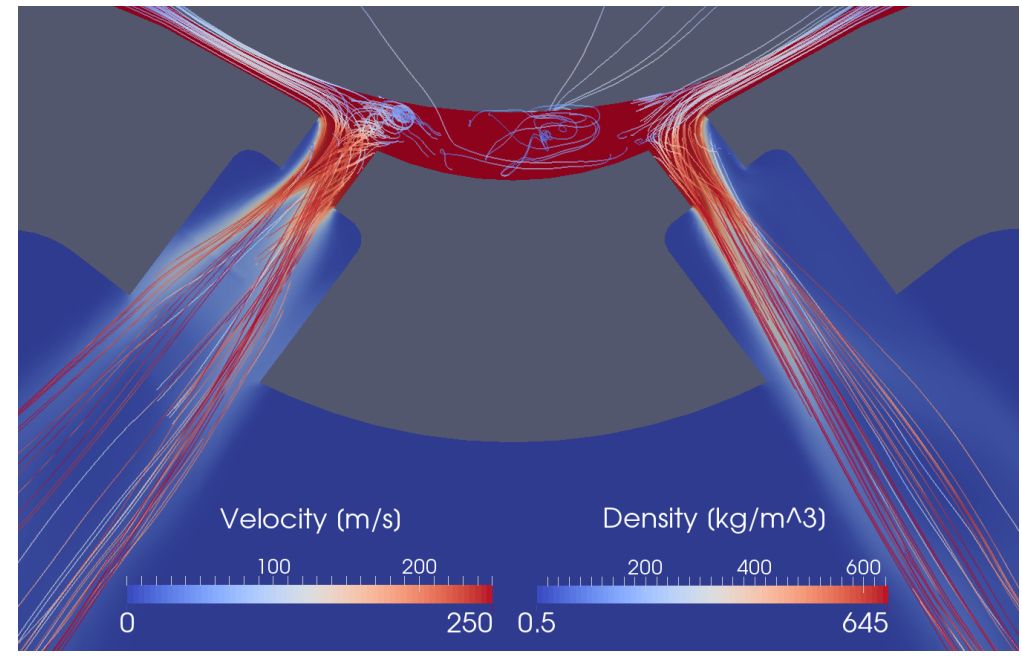

Figure 19: The expansion of the spray angle caused by string flash-boiling. Taken midway through flashing simulation. Streamlines are colored by velocity magnitude and the cut plane is colored by density.

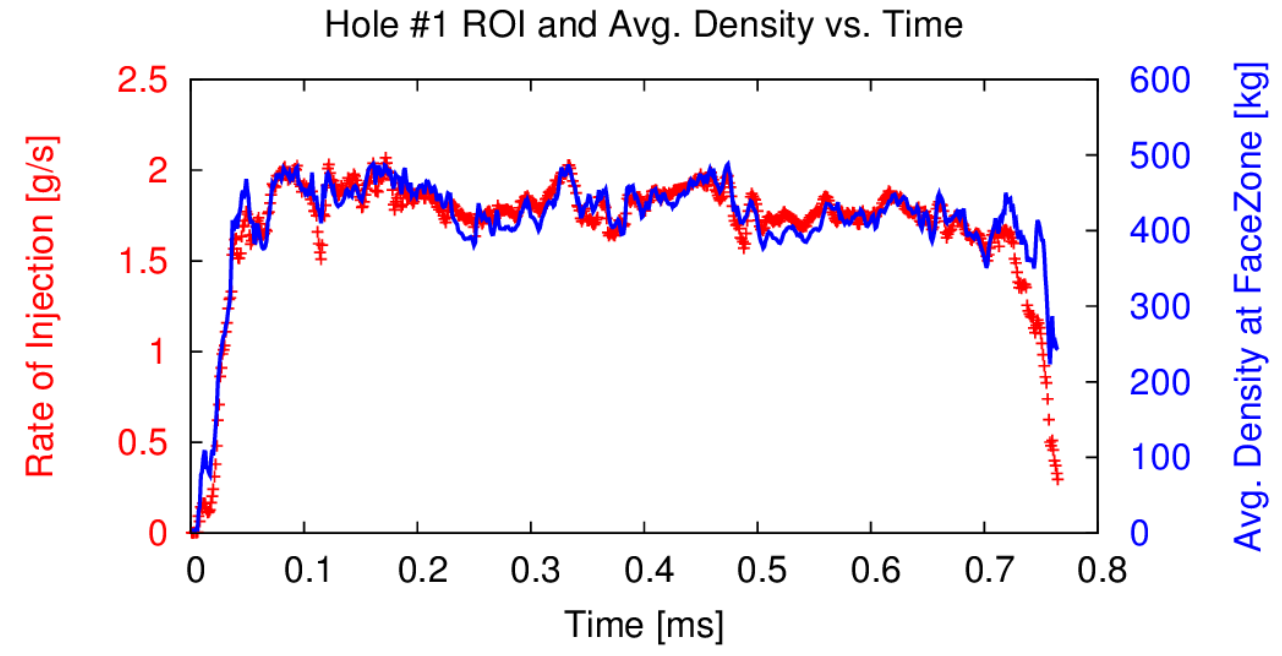

Figure 20: Rate of injection and average density across hole \#1 cut plane.

in the average density are due to vapor generation at the inlet corner and vapor generation through string flash-boiling. These oscillations are clearly the dominating influence on fluctuations in the nozzle hole ROI and in the 
hole-to-hole variation in mass flow rate.

\section{Conclusions}

Spray G flashing and non-flashing injection has been simulated with transient needle motion. The primary results are summarized below:

- The results demonstrate the ability of CFD simulations to capture the rate of injection by prescribing the upstream pressure and lifting the needle with dynamic mesh motion.

- The results were qualitatively validated against experimental imaging, capturing spray angle expansion and perturbation due to the closing of the needle, predicting the presence or lack of ambient gas ingestion into the counter-bore, and capturing the oscillation frequency in the spray plumes.

- At low lift conditions vapor generation is observed in the seat area as the fuel flows past the narrow region of the needle.

- Needle wobble is shown to have no measurable influence on the holeto-hole variation in mass flow rate and spray structure. However, the needle to needle-guide clearance in these simulations may have been overestimated and the use of an ensemble averaged motion profile may have diminished the magnitude of the wobble. Further investigation may be justified as higher fidelity experimental characterization of the needle motion and needle-guide clearance becomes available.

- The complex flow contained within the fuel injector sac is analyzed and shown to contain transient interacting vortices which result in string flash-boiling, perturbations in spray angle and direction, and oscillations in mass flow rate.

- The oscillations in mass flow rate are ultimately attributed to the presence of vapor within the nozzle holes decreasing the average flow density.

The discovery and investigation of the complex internal flow in this microsac GDI injector is a novel and interesting result. The behavior of these sprays is absolutely dependent upon this internal flow and it can only be 
captured through 3D simulation with sufficient grid resolution within the sac region. The implications of these findings are significant as they explain the mechanism behind the perturbations and expansions of individual spray plumes. Understanding this mechanism might allow for the control of these perturbations and expansions in the next generation of GDI nozzles, resulting in a more predictable, cleaner spray.

Future computational work will include a comparison to experimental Xray tomography data for downstream mass distribution and comparison to flow through an as-built geometry. Furthermore, experimental validation of the complex internal flow structures may be possible in the near future with the use of transparent injectors.

\section{Acknowledgements}

The authors would like to acknowledge the financial support of General Motors, who has sponsored much of the development of this CFD solver.

The mesh used in these simulations was generated using GridPro meshing software. The authors gratefully acknowledge the assistance provided by GridPro in helping to exploit their tool to generate such a complex grid.

The X-ray needle lift experiments were performed at the 32-ID beam line of the APS at Argonne National Laboratory. Use of the APS is supported by the U.S. Department of Energy (DOE) under Contract No. DE-AC0206CH11357. Argonne's fuel spray research is sponsored by the DOE Vehicle Technologies Program, under the direction of Gurpreet Singh and Leo Breton.

\section{References}

[1] Engine Combustion Network, http://www.sandia.gov/ecn/index.php.

[2] Aleiferis, P. G. and Van Romunde, Z. R., An analysis of spray development with iso-octane, n-pentane, gasoline, ethanol and n-butanol from a multi-hole injector under hot fuel conditions, Fuel, vol. 105, pp. 143-168, 2013.

[3] Aori, G., Hung, D. L. S., Zhang, M., Zhang, G., and Li, T., Effect of Nozzle Configuration on Macroscopic Spray Characteristics of Multi-Hole Fuel Injectors Under Superheated Conditions, Atomization and Sprays, vol. 26, no. 5, pp. 439-462, 2016. 
[4] Battistoni, M., Xue, Q., Som, S., and Pomraning, E., Effect of Off-Axis Needle Motion on Internal Nozzle and Near Exit Flow in a Multi-Hole Diesel Injector, SAE Int. J. Fuels Lubr., vol. 7, no. 1, pp. 167-181, 2014.

[5] Befrui, B., Corbinelli, G., Spiekermann, P., Shost, M., and Lai, M.-C., Large Eddy Simulation of GDI Single-Hole Flow and Near-Field Spray, SAE Int. J. Fuels Lubr., vol. 5, no. 2, pp. 620-636, 2012.

[6] Berndorfer, A., Breuer, S., Poick, W., and Von Bacho, P., Diffusion Combustion Phenomena in GDi Engines caused by Injection Process, Tech. Rep. 2013-01-0261, SAE, 2013.

[7] Bilicki, Z. and Kestin, J., Physical Aspects of the Relaxation Model in TwoPhase Flow, Proceedings of the Royal Society A: Mathematical, Physical and Engineering Sciences, Vol. 428, pp. 379-397, 1990.

[8] Blessinger, M., Manin, J., Skeen, S. A., Meijer, M., Parrish, S., and Pickett, L. M., Quantitative mixing measurements and stochastic variability of a vaporizing gasoline direct-injection spray, International Journal of Engine Research, vol. 16, no. 2, pp. 238-252, 2015.

[9] Colarossi, M., Trask, N., Schmidt, D. P., and Bergander, M. J., Multidimensional modeling of condensing two-phase ejector flow, International Journal of Refrigeration, vol. 35, no. 2, pp. 290-299, 2012.

[10] Dahms, R. N., Manin, J., Pickett, L. M., and Oefelein, J. C., Understanding high-pressure gas-liquid interface phenomena in Diesel engines, Proceedings of the Combustion Institute, vol. 34, no. 1, pp. 1667-1675, 2013.

[11] Dahms, R. N. and Oefelein, J. C., On the transition between two-phase and single-phase interface dynamics in multicomponent fluids at supercritical pressures, Physics of Fluids, vol. 25, no. 9, 2013.

[12] Desantes, J. M., Garcia-Oliver, J. M., Pastor, J. M., Pandal, A., Baldwin, E., and Schmidt, D. P., Coupled/Decoupled Spray Simulation Comparison of the ECN Spray A Condition with the $\Sigma$-Y Eulerian Atomization Model, International Journal of Multiphase Flow, vol. 80, pp. 89-99, 2016.

[13] Desantes, J. M., Payri, R., Gimeno, J., and Marti-Aldaravi, P., Simulation of the First Millimeters of the Diesel Spray by an Eulerian Spray Atomization Model Applied on ECN Spray A Injector, Tech. Rep. 2014-01-1418, SAE, 2014 . 
[14] Downar-Zapolski, P., Bilicki, Z., Bolle, L., and Franco, J., The nonequilibrium relaxation model for one-dimensional flashing liquid flow, International Journal of Multiphase Flow, vol. 22, no. 3, pp. 473-483, 1996.

[15] Duke, D., Swantek, A., Tilocco, Z., Kastengren, A., Fezzaa, K., Neroorkar, K., Moulai, M., Powell, C., and Schmidt, D., X-ray Imaging of Cavitation in Diesel Injectors, SAE Int. J. Engines, vol. 7, no. 2, pp. 1003-1016, 2014.

[16] Duke, D. J., Swantek, A., Tilocco, Z., Kastengren, A. L., Fezzaa, K., Neroorkar, K., Moulai, M., Powell, C., and Schmidt, D. P., X-ray Imaging of Cavitation in Diesel Injectors, SAE Int. J. Engines, 2014.

[17] Garcia-Oliver, J. M., Pastor, J. M., Pandal, A., Trask, N., Baldwin, E., and Schmidt, D. P., Diesel Spray Cfd Simulations Based on the $\Sigma$ - $\Upsilon$ Eulerian Atomization Model, Atomization and Sprays, vol. 23, no. 1, pp. 71-95, 2013.

[18] Gopalakrishnan, S. and Schmidt, D., A computational study of flashing flow in fuel injector nozzles, SAE Int. J. Engines, vol. 1, no. 1, pp. 160-170, 2009.

[19] Kastengren, A., Powell, C., Tilocco, F., Liu, Z., Moon, S., Zhang, X., and Gao, J., Correlation of Split-Injection Needle Lift and Spray Structure, SAE Journal, pp. 2011-01-0383, 2011.

[20] Kastengren, A. L., Tilocco, F. Z., Powell, C. F., Manin, J., Pickett, L. M., Payri, R., Bazyn, T., Termicos, C. M. T. M., and Valencia, U. P. D., Engine Combustion Network (ECN): Measurements of Nozzle Geometry and Hydraulic Behavior, Atomization and Sprays, vol. 22, no. 12, pp. 1011-1052, 2012.

[21] Lemmon, E., Huber, M., and McLinden, M., NIST Standard Reference Database 23: Reference Fluid Thermodynamic and Transport PropertiesREFPROP, Version 9.1, National Institute of Standards and Technology, Standard Reference Data Program, Gaithersburg, 2013.

[22] Manin, J., Kastengren, A. L., and Payri, R., Understanding the Acoustic Oscillations Observed in the Injection Rate of a Common-Rail Direct Injection Diesel Injector, Journal of Engineering for Gas Turbines and Power, vol. 134, no. 12, p. 122801, 2012.

[23] Moulai, M., Grover, R., Parrish, S., and Schmidt, D., Internal and NearNozzle Flow in a Multi-Hole Gasoline Injector Under Flashing and NonFlashing Conditions, Tech. Rep. 2015-01-0944, SAE, 2015. 
[24] Negro, S. and Bianchi, G. M., Superheated fuel injection modeling: An engineering approach, International Journal of Thermal Sciences, vol. 50, no. 8, pp. 1460-1471, 2011.

[25] Neroorkar, K. and Schmidt, D., A Computational Investigation of FlashBoiling Multi-hole Injectors with Gasoline-Ethanol Blends, Tech. Rep. 201101-0384, SAE, 2011.

[26] Neroorkar, K. and Schmidt, D. P., Modeling of vapor-liquid equilibrium of gasoline-ethanol blended fuels for flash boiling simulations, Fuel, vol. 90, no. 2, pp. 665-673, 2011.

[27] Neroorkar, K., Shields, B., Grover, Jr., R., Plazas Torres, A., and Schmidt, D., Application of the Homogeneous Relaxation Model to Simulating Cavitating Flow of a Diesel Fuel, Tech. Rep. 2012-01-1269, SAE, 2012.

[28] Neroorkar, K. D., Modeling of Flash Boiling Flows in Injectors with GasolineEthanol Fuel Blends, Phd, University of Massachusetts - Amherst, 2011.

[29] Ning, W., Reitz, R. D., Diwakar, R., and Lippert, A. M., An EulerianLagrangian Spray and Atomization Model With Improved Turbulence Modeling, Atomization and Sprays, vol. 19, no. 8, pp. 727-739, 2009.

[30] Oza, R. and Sinnamon, J., An experimental and analytical study of flashboiling fuel injection, Tech. Rep. 830590, SAE, 1983.

[31] Parrish, S. E., Zink, R. J., Sivathanu, Y., and Lim, J., Spray patternation of a multi-hole injector utilizing planar line-of-sight extinction tomography, ILASS Americas, 22nd Annual Conference on Liquid Atomization and Spray Systems, 2010.

[32] Postrioti, L., Bosi, M., Cavicchi, A., AbuZahra, F., Gioia, R. D., and Bonandrini, G., Momentum Flux Measurement on Single-Hole GDI Injector under Flash-Boiling Condition, Tech. Rep. 2015-24-2480, SAE, 2015.

[33] Powell, C., Kastengren, A., Liu, Z., and Fezzaa, K., The Effects of Diesel Injector Needle Motion on Spray Structure, Journal of Engineering for Gas Turbines and Power, vol. 133, no. 1, pp. 012802-012802-9, 2011.

[34] Saha, K., Som, S., Battistoni, M., Li, Y., Pomraning, E., and Senecal, P. K., Numerical Investigation of Two-Phase Flow Evolution of In- and Near-Nozzle Regions of a Gasoline Direct Injection Engine During Needle Transients, SAE International Journal of Engines, vol. 9, no. 2, pp. 2016-01-0870, 2016. 
[35] Saha, K., Som, S., Battistoni, M., Li, Y., Quan, S., and Senecal, P. K., Modeling of Internal and Near-Nozzle Flow for a GDI Fuel Injector, Proceedings of the ASME 2015 Internal Combustion Engine Division Fall Technical Conference, 2015.

[36] Salvador, F. J., Gimeno, J., Pastor, J. M., and Martí-Aldaraví, P., Effect of turbulence model and inlet boundary condition on the Diesel spray behavior simulated by an Eulerian Spray Atomization (ESA) model, International Journal of Multiphase Flow, vol. 65, pp. 108-116, 2014.

[37] Schmidt, D. P., Corradini, M. L., and Rutland, C. J., A two-dimensional, nonequilibrium model of flashing nozzle flow, Proceedings of the 3rd ASME/JSME Joint Fluids Engineering Conference, San Francisco, California, 1999.

[38] Schmidt, D. P., Gopalakrishnan, S., and Jasak, H., Multi-dimensional simulation of thermal non-equilibrium channel flow, International Journal of Multiphase Flow, vol. 36, no. 4, pp. 284-292, 2010.

[39] Serras-Pereira, J., Van Romunde, Z., Aleiferis, P. G., Richardson, D., Wallace, S., and Cracknell, R. F., Cavitation, primary break-up and flash boiling of gasoline, iso-octane and n-pentane with a real-size optical direct-injection nozzle, Fuel, vol. 89, no. 9, pp. 2592-2607, 2010.

[40] Shen, Q., Lee, W.-K., Fezzaa, K., Chu, Y., De Carlo, F., Jemian, P., Ilavsky, J., Erdmann, M., and Long, G., Dedicated full-field X-ray imaging beamline at Advanced Photon Source, Nuclear Instruments and Methods in Physics Research Section A: Accelerators, Spectrometers, Detectors and Associated Equipment, vol. 582, no. 1, pp. 77-79, 2007.

[41] Sher, E., Bar-Kohany, T., and Rashkovan, A., Flash-boiling atomization, Progress in Energy and Combustion Science, vol. 34, no. 4, pp. 417-439, 2008 .

[42] Shost, M. A., Lai, M.-C., Befrui, B., Spiekermann, P., and Varble, D. L., GDI Nozzle Parameter Studies Using LES and Spray Imaging Methods, Tech. Rep. 2014-01-1434, SAE, 2014.

[43] Strek, P., Schmidt, D., and Duke, D., X-ray Radiography and CFD Studies of the Spray G Injector, SAE 2016 World Congress \& Exhibition, Detroit, MI, 2016. 
[44] Vallet, A., Burluka, A. A., and Borghi, R., Development of a Eulerian Model for the "Atomization" of a Liquid Jet, Atomization and Sprays, vol. 11, pp. 619-642, 2001.

[45] Van Romunde, Z. and Aleiferis, P., Effect of Operating Conditions and Fuel Volatility on Development and Variability of Sprays From Gasoline DirectInjection Multihole Injectors, Atomization and Sprays, vol. 19, no. 3, pp. 207-234, 2009.

[46] Viera, J., Payri, R., Swantek, A., Duke, D., Sovis, N., Kastengren, A., and Powell, C., Linking instantaneous rate of injection to X-ray needle lift measurements for a direct-acting piezoelectric injector, Energy Conversion and Management, vol. 112, no. C, pp. 350-358, 2016.

[47] Weller, H., Tabor, G., Jasak, H., and Fureby, C., A tensorial approach to computational continuum mechanics using object-oriented techniques, Computers in Physics, vol. 12, no. 6, p. 620, 1998.

[48] Xu, M., Zhang, Y., Zeng, W., Zhang, G., and Zhang, M., Flash Boiling: Easy and Better Way to Generate Ideal Sprays than the High Injection Pressure, SAE Int. J. Fuels Lubr., vol. 6, no. 1, pp. 137-148, 2013.

[49] Xue, Q., Battistoni, M., Powell, C., Longman, D., Quan, S., Pomraning, E., Senecal, P., Schmidt, D., and Som, S., An Eulerian CFD model and X-ray radiography for coupled nozzle flow and spray in internal combustion engines, International Journal of Multiphase Flow, vol. 70, pp. 77-88, 2015.

[50] Xue, Q., Battistoni, M., Som, S., Quan, S., Senecal, P. K., Pomraning, E., and Schmidt, D. P., Eulerian CFD Modeling of Coupled Nozzle Flow and Spray with Validation Against X-Ray Radiography Data, SAE International Journal of Engines, vol. 7, no. 2, 2014.

[51] Zeng, W., Xu, M., Zhang, G., Zhang, Y., and Cleary, D. J., Atomization and vaporization for flash-boiling multi-hole sprays with alcohol fuels, Fuel, vol. 95, pp. 287-297, 2012.

[52] Zeng, W., Xu, M., Zhang, M., Zhang, Y., and Cleary, D. J., Macroscopic characteristics for direct-injection multi-hole sprays using dimensionless analysis, Experimental Thermal and Fluid Science, vol. 40, pp. 81-92, 2012.

[53] Zhang, G., Xu, M., Zhang, Y., Zhang, M., and Cleary, D. J., Macroscopic Characterization of Flash-Boiling Multihole Sprays Using Planar LaserInduced Exciplex Fluorescence. Part II: Cross-Sectional Spray Structure, Atomization and Sprays, vol. 23, no. 3, pp. 265-278, 2013. 
[54] Zhang, M., Drake, M. C., and Peterson, K., Simultaneous high-speed imaging of fuel spray, combustion luminosity, and soot luminosity in a spray-guided direct injection engine with different multi-hole fuel injectors, Proceedings of the ASME 2013 Internal Combustion Engine Division Fall Technical Conference, Dearborn, Michigan, 2013. 